\title{
SARS-CoV-2 triggers Golgi fragmentation via downregulation of GRASP55 to facilitate viral trafficking
}

Jianchao Zhang ${ }^{1, *}$, Andrew Kennedy ${ }^{2, *}$, Lijuan Xing ${ }^{1}$, Sarah Bui ${ }^{1}$, Whitney Reid ${ }^{1}$, Joseph Joppich ${ }^{1}$, Erpan Ahat ${ }^{1}$, Molly Rose ${ }^{1}$, Qiyi Tang ${ }^{3}$, Andrew W. Tai ${ }^{2,4, \#}$, and Yanzhuang Wang $1,5,6, \#$

${ }^{1}$ Department of Molecular, Cellular and Developmental Biology, University of Michigan, Ann Arbor, MI 48109, USA.

${ }^{2}$ Division of Gastroenterology, Department of Internal Medicine, University of Michigan Medical School, Ann Arbor, MI 48109, USA

${ }^{3}$ Department of Microbiology, Howard University College of Medicine, Washington, DC 20059, USA.

${ }^{4}$ Department of Microbiology and Immunology, University of Michigan Medical School, Ann Arbor, MI 48109, USA.

${ }^{5}$ Department of Neurology, University of Michigan School of Medicine, Ann Arbor, MI 48109, USA.

${ }^{6}$ Lead Contact

* These authors contributed equally to this work.

\#Correspondence: andrewwt@med.umich.edu (A.W.T.) and yzwang@umich.edu (Y.W.)

\section{Keywords}

SARS-CoV-2; Golgi; fragmentation; trafficking; GRASP55; TGN46

\section{Running title}

SARS-CoV-2 remodels the Golgi to accelerate viral trafficking 


\section{Abstract}

The ongoing COVID-19 pandemic is caused by severe acute respiratory syndrome coronavirus 2 (SARS-CoV-2), an enveloped RNA virus. Despite the high economic and life losses caused by SARS-CoV-2, the detailed viral cycle, especially how it assembles and traffics in the secretory pathway, remains largely unknown. Here, we showed that SARS-CoV-2 infection induces global alterations of the host endomembrane system, including dramatic Golgi fragmentation. Disrupting Golgi function with small molecules strongly inhibits viral infection. Furthermore, expression of several SARS-CoV-2 proteins individually is sufficient to trigger Golgi fragmentation. Significantly, SARS-CoV-2 infection down-regulates GRASP55 but up-regulates TGN46 expression, while expression of GRASP55 or knockdown of TGN46 reduces the infection rate of both USA-WA1 and Delta variants of SARS-CoV-2. Our study reveals that SARS-CoV-2 modulates Golgi structure and function via altering GRASP55 and TGN46 expression to facilitate viral trafficking, indicating the Golgi as a novel therapeutic target to block SARS-CoV-2 infection. 


\section{Introduction}

Since December 2019, an unprecedented pandemic caused by coronavirus disease 2019 (COVID-19) has raised a serious threat to human health worldwide. SARS-CoV-2 (severe acute respiratory syndrome coronavirus 2), the causative agent for COVID-19, is an enveloped, single-stranded positive-sense RNA virus in the beta-coronavirus family. Despite the extremely high economic and life losses caused by SARS-CoV-2, there are few effective antiviral therapies. Vaccination is currently the most critical and effective strategy to prevent COVID-19 from spreading. However, vaccines are not effective in all individuals, such as the immunocompromised, and the emergence of SARS-CoV-2 variants with higher transmissibility or possibly higher pathogenicity poses a great challenge to the existing vaccines (Planas et al., 2021). Therefore, it is urgent and important to elucidate the detailed mechanisms of SARS-CoV-2 infection, and thus develop various strategies to block the replication and spread of all variants.

Entry into host cells is the first step of virus infection and acts as a determinant of viral infectivity and pathogenesis. Since the pandemic outbreak, the cell entry mechanisms of SARS-CoV-2 have been extensively explored. Like SARS-CoV, SARS-CoV-2 employs human angiotensin-converting enzyme 2 (ACE2) as the entry receptor. The spike (S) protein on the virus interacts with ACE2 at the host cell surface, allowing the virus to attach to the host cell membrane. After cleavage by the transmembrane serine protease 2 (TMPRSS2), the spike protein is activated and initiates a fusion process of the viral membrane with the host cell plasma membrane. When TMPRSS2 is absent, SARS-CoV-2 is endocytosed and the spike protein is activated by Cathepsin B and L (CatB/L) inside the lysosomal lumen (Hoffmann et al., 2020a). Compared to SARS-CoV, the spike protein of SARSCoV-2 possesses a unique furin cleavage site that remarkably facilitates its cell entry and contributes to its higher infectivity (Shang et al., 2020). Following entry, the genomic RNA is released into the cytoplasm. The polyproteins ppla and pplab translated from two large open reading frames, ORF1a and ORF1b, are self-processed into 16 individual non-structural proteins (Nsps), which modulate the endoplasmic reticulum (ER) to form double-membrane vesicles (DMVs) where the viral replication and transcription complex (RTC) is anchored to produce abundant viral RNAs (Khoury et al., 2020).

In addition to the $16 \mathrm{Nsps}$, the SARS-CoV-2 genome also encodes four structural (S, M, E, and N) and 9 accessory proteins (Gordon et al., 2020). Three of the four viral structural proteins (S, E, and M) are synthesized in the ER and transported to the ER-to-Golgi intermediate compartment (ERGIC), where virions are assembled and budded into the lumen of the ERGIC and Golgi. In the ER and Golgi, the spike protein is highly glycosylated (Sanda et al., 2021; Tian et al., 2021), which 
affects its folding, stability, interaction with ACE2, and susceptibility to vaccines. Integrative imaging revealed that SARS-CoV-2 infection triggers Golgi fragmentation (Cortese et al., 2020), but the cause and consequence of Golgi fragmentation remain largely elusive. While it was generally believed that mature viral particles are carried by Golgi-derived vesicles to the plasma membrane and secreted to the extracellular space (Westerbeck and Machamer, 2015, 2019), which is also supported by recent publications (Eymieux et al., 2021), some other reports indicated that SARSCoV-2 virus may be released by lysosomal exocytosis (Chen et al., 2021; Ghosh et al., 2020). Thus, the route that mediates SARS-CoV-2 trafficking from the Golgi to the extracellular space is still controversial.

Here, we systematically investigated the interaction between SARS-CoV-2 and the host endomembrane system. Our study revealed that SARS-CoV-2 infection causes a dramatic disruption of the Golgi structure, which can be recapitulated by the expression of individual SARS-CoV-2 proteins. Disruption of Golgi homeostasis by small molecules significantly reduces viral infection. By surveying a large number of Golgi proteins, we found that SARS-CoV-2 infection reduces GRASP55 but increases TGN46 expression. Conversely, expression of GRASP55 or depletion of TGN46 in cells significantly inhibits viral infection and secretion. Therefore, our study uncovered a novel mechanism by which SARS-CoV-2 remodels the Golgi structure to facilitate viral release, suggesting the Golgi as a novel drug target for COVID-19 treatment.

\section{Results}

\section{SARS-CoV-2 infection induces dramatic morphological alterations of multiple subcellular organelles, in particular the Golgi}

Viruses can be simply categorized into enveloped viruses and non-enveloped viruses. Non-enveloped viruses usually exit cells through cytolytic mechanisms, while enveloped viruses often utilize the host secretory pathway to assemble and bud out of the cell (Welsch et al., 2007). How SARS-CoV-2, an enveloped beta-coronavirus, modulates the endomembrane system for its assembly and exit is an important but unanswered question. To address this question, we performed morphological analyses of multiple subcellular organelles in the secretory pathway, including the ER, ERGIC, Golgi, autophagosome, endosome, and lysosome, in SARS-CoV-2-infected Huh7-ACE2 cells, a permanent cell line established from male hepatoma tissue that is often used in studies of SARS-CoV-2 infection (Sherman et al., 2021). After $24 \mathrm{~h}$ infection by SARS-CoV-2 (USA-WA1 strain, same as below unless specified), the ER structure marked by calreticulin was not dramatically altered (Table 
1, Figure S1). ERGIC53 was normally concentrated in the perinuclear region in uninfected cells, while in SARS-CoV-2 infected cells it displayed as dispersed puncta distributed in the cytoplasm (Figures 1A and 1B). Further quantitation of the images indicated that the total area of ERGIC53 did not change (Figure 1C), and its relative expression level was modestly reduced (Figure 1D).

The Golgi structure was significantly affected by SARS-CoV-2 infection. In contrast to the wellorganized ribbon-like structure in uninfected cells, as labeled by the Golgi protein GPP130, the Golgi was seen as small fragments dispersed in the entire cytoplasm in infected cells (Figure 1E-F), although the total area and expression level of GPP130 did not change (Figure 1G-H). In control cells, COPI, COPII, and clathrin coats, indicated by $\beta$-COP, Sec31, and clathrin heavy chain, respectively, are accumulated in the perinuclear region; whereas in SARS-CoV-2 infected cells they are also dispersed in the cytoplasm (Figure S1), consistent with Golgi fragmentation.

The endosome/lysosome system was also affected by SARS-CoV-2 infection. The early endosome marker EEA1 and the late endosome marker Rab7 both exhibited as larger puncta in infected cells (Figures $1 \mathrm{M}-\mathrm{Q}$ ), indicating aggregation of the membranes. While EEA1 expression level did not change (Figures 1K-L), Rab7 was up-regulated (Figures 1O-P), suggesting a growth of late endosomes. The aggregation of endosome/lysosome membranes was confirmed using the late endosome/lysosome marker LAMP2, which displayed fewer but larger puncta in infected cells (Figures 1Q-T). In addition, minor or modest effects were observed for LC3 and Cathepsin D (Figure S2A-H), which represent autophagosome and active lysosomes, respectively. While microtubule cytoskeleton appeared to be partially depolymerized, actin microfilament did not seem to change in SARS-CoV-2 infected cells (Figure S2I-N). Taken together, SARS-CoV-2 infection alters the structure of ERGIC, Golgi, endosome, and lysosome.

\section{Disrupting Golgi functions by small molecules inhibits SARS-CoV-2 infection}

We reasoned that the morphological changes of the endomembrane system may facilitate SARS$\mathrm{CoV}-2$ infection, and if so, disrupting the functions of these membrane organelles may impact viral infection. Therefore, we performed a small library drug screen to determine whether molecules targeting the endomembrane system could inhibit SARS-CoV-2 infection. Prior to the experiment, we titrated the chemical compounds and picked up the highest dose that did not cause cell death. We then used this concentration to treat cells during SARS-CoV-2 infection. Among a total of 27 drugs tested, 22 drugs displayed significant inhibitory effects on SARS-CoV-2 infection (Figure 2A-B). 
Three ER stress inducers, thapsigargin (Tg, a SERCA calcium pump inhibitor), tunicamycin (Tm, a protein glycosylation inhibitor), and dithiothreitol (DTT, a reducing agent that disrupts disulfide bonds of proteins), significantly inhibited viral infection. Interestingly, distinct from $\mathrm{Tg}$, ionomycin (Iono), a calcium ionophore that triggers calcium influx across the plasma membrane as well as ER membranes, exhibited no effect on viral infection. Two Golgi function modulators, Brefeldin A (BFA, a fungal product that inhibits ER-to-Golgi trafficking) and monensin (an ionophore that inhibits trans-Golgi transport), displayed over 98\% inhibition of viral infection, suggesting an important role of the Golgi in SARS-CoV-2 infection.

\section{Chemicals interfering with lysosome functions and protein homeostasis inhibit SARS-CoV-2 infection}

The lysosome is a key subcellular organelle in both endocytic and exocytic pathways essential for viral entry and secretion. Indeed, disruption of lysosomal functions with either bafilomycin A1 (BafA1, an inhibitor of vacuolar-type $\mathrm{H}^{+}$-ATPase that blocks autolysosome acidification), chloroquine (CQ, an FDA-approved antimalarial drug that increases the $\mathrm{pH}$ of the acid vesicles), Vacuolin-1 (a cell-permeable compound that can induce large and swollen lysosomes), a cocktail of protease inhibitors (PIs, which inhibit a broad range of cellular proteases), or the three lysosome protease inhibitors (E64d, leupeptin, and pepstatin, which inhibit lysosomal hydrolases), significantly reduced viral infection (Figure 2A-B). Interestingly, both autophagy inducer (Torin-1) and autophagy inhibitors, 3-methyladenine (3-MA) and CID 1067700 (CID), displayed similar inhibitory effects on the viral infection rate, although to a lesser degree than lysosomal inhibitors, implying that autophagy may also be involved in SARS-CoV-2 infection as previously suggested (Gorshkov et al., 2021).

Proteostasis network is usually hijacked by viruses to satisfy the high demands for viral protein synthesis and folding (Aviner and Frydman, 2020). Therefore, we blocked proteosome-mediated protein degradation and tested the effect on SARS-CoV-2 infection (Figure 2A-B). Inhibition of proteasome-mediated protein degradation with MG132 (a 26S proteosome complex inhibitor) potently inhibited viral infection, while inhibition of ubiquitin conjugation by PYR-41 (an E1 ubiquitin-activating enzyme inhibitor) displayed no effect. While it is possible that a higher concentration of PYR-41 is required to entirely block the first step of ubiquitination, alternatively, the virus may possess the capability to bypass the E1 enzyme as some bacteria (Qiu et al., 2016). Inhibition of the AAA ATPase p97/VCP with CB-5083, UPCDC-30245, or NMS-873 also significantly reduced viral infection, indicating that the proteostasis pathway may serve as a potential 
target for the treatment of COVID-19. In addition, three protease inhibitors, PF-429242 (a site-1 protease inhibitor), Decanoyl-RVKR-CMK (a furin inhibitor), and camostat mesylate (a TMPRSS2 inhibitor), displayed modest inhibitory effects on SARS-CoV-2 infection, while aprotinin (an inhibitor of serine proteases including trypsin, chymotrypsin, and plasmin) had no effect.

Latrunculin B (LatB, an actin polymerization inhibitor) did not inhibit viral infection, but nocodazole (Noc, a microtubule polymerization inhibitor) exhibited about $50 \%$ inhibition of viral infection (Figure 2A-B), consistent with a previous report that the microtubule cytoskeleton is required for SARS-CoV-2 infection (Cortese et al., 2020). In our study, neither staurosporine (STS, a broadspectrum protein kinase inhibitor) nor okadaic acid (OA, an inhibitor of several serine/threonine phosphatases) showed significant effect on viral infection (Figure 2A-B).

To confirm these observations, we selected 9 most effective inhibitors, which target the ER (Tg), Golgi (BFA and monensin), lysosome (BafA1, CQ, Vaculin-1, and 3-inhibitors), and protein homeostasis (MG132 and CB-5083), respectively, and performed dose-response assays on SARSCoV-2 infection. All 9 compounds, in particular, Tg, BFA, monensin, BafA1, and 3-inhibitors, dramatically and consistently inhibited SARS-CoV-2 infection even at much lower concentrations (Figure 2C, Figure S3). Taken together, disruption of Golgi and lysosome functions robustly inhibited SARS-CoV-2 infection, suggesting a critical role of the Golgi and lysosome in SARS-CoV2 infection.

\section{SARS-CoV-2 infection dramatically alters the Golgi structure}

To better understand the role of the Golgi in SARS-CoV-2 infection, we systematically analyzed the Golgi structure in SARS-CoV-2 infected cells by immunofluorescence and electron microscopy (EM). Using GRASP65, $\beta-1$, 4-Galactosyltransferase 1 (GalT), and Golgin-245 to represent the cisGolgi, trans-Golgi, and trans-Golgi network, respectively, we found that all sub-compartments of the Golgi were dramatically fragmented after SARS-CoV-2 infection (Figure 3A-K). Despite the dispersal of the Golgi in virus-infected cells (Figure 3B-C, 3G-H, and 3L-M), the Golgi area and the expression of GRASP65 and GalT remained unchanged, while the level of Golgin-245 was reduced (Figure 3D-E, 3I-J, and 3N-O). 3D reconstruction of the Golgi demonstrated that spike was highly enriched in the Golgi fragments in SARS-CoV-2 infected cells (Movie S1; Movie S2), indicating an important role of the Golgi in viral infection.

Under EM, the Golgi displayed dramatically different features between uninfected and SARS-CoV-2 
infected cells (Figure 3P, Figure S4). In uninfected cells, the Golgi was highly concentrated in the perinuclear region and displayed long cisterna and stacked structures. In infected cells, the Golgi stacks were severely disorganized and fragmented, with most Golgi membranes vesiculated. Interestingly, many virus particles were observed inside the swollen Golgi lumen, suggesting that SARS-CoV-2 traffics through the Golgi apparatus and causes Golgi fragmentation. Consistent with previous reports (Cortese et al., 2020), we also observed a number of DMVs marked by black arrowheads (Figure 3P). Taken together, SARS-CoV-2 infection triggers severe Golgi fragmentation.

\section{Expression of S, M, E, and ORF3a viral proteins triggers Golgi fragmentation}

To explore the molecular mechanisms by which Golgi fragmentation is induced after SARS-CoV-2 infection, we expressed 8 Flag-tagged SARS-CoV-2 proteins in Vero E6 cells and determined their effects on the Golgi morphology (Figure 4A). The S, M, and E viral proteins have a signal peptide that can target them into the ER and then are transported to the Golgi. Unexpectedly, expression of not only S, M, and E viral proteins, but also ORF3a and NSP15, significantly altered the Golgi structure and induced Golgi fragmentation; while expression of N, ORF7a, or ORF6 displayed no significant effect (Figure 4B-C). While it has been shown that expression of ORF3a of SARS-CoV (Freundt et al., 2010) or SARS-CoV-2 (Gonzales and Machamer, 2021) triggered Golgi fragmentation, so far it has not been reported that expression of other individual viral structural proteins (S, M, and E) can also induce Golgi fragmentation.

Our results described above indicated that SARS-CoV-2 infection may cause Golgi fragmentation via altering the expression level of Golgi structural proteins. Although the effects of the Flag-tagged viral proteins on the Golgi morphology were clear, due to their relatively low transfection rate and expression level, they were not adequate to show the effect of viral proteins on the overall expression of Golgi proteins by western blot. To further understand how SARS-CoV-2 viral proteins modulate the Golgi apparatus, we expressed the same 8 viral proteins with Strep tags, whose transfection and expression levels were higher than the Flag-tagged proteins, and determined their effect on Golgi and endosome/lysosome proteins (Figure 4D; Figure S5). Expression of S and Nsp15 greatly decreased the level of GRASP55, a protein critical for Golgi structure formation (Shorter et al., 1999; Xiang and Wang, 2010), which most likely accounts for Golgi fragmentation. Expression of M, E or ORF3a did not affect GRASP55 protein levels, indicating that S and Nsp15 employ different mechanisms to induce Golgi fragmentation. In contrast to the reduction of GRASP55, TGN46 expression was elevated upon ORF3a and ORF6 expression. ORF3a expression also increased the precursor of Cathepsin D, a lysosomal enzyme that is processed in the late Golgi, indicating a defect in lysosomal 
biogenesis due to Golgi fragmentation. Taken together, expression of S, M, E or ORF3a is sufficient to trigger Golgi fragmentation.

\section{SARS-CoV-2 infection down-regulates GRASP55 and up-regulates TGN46 expression}

To further investigate the molecular mechanisms of Golgi fragmentation induced by viral infection, we analyzed the morphology and expression level of more Golgi proteins in SARS-CoV-2 infected cells by immunofluorescence microscopy. Consistent with results from the Golgi markers tested above (Figure 1E; Figure 3A, F, and K), GCC88 and Arl1 also showed a remarkably higher Golgi fragmentation ratio and Golgi item number in infected cells (Figure S6A-C and S6F-H), with an unchanged Golgi area and marginally changed expression level (Figure S6D-E and S6I-J). Similarly, the Golgi structure marked by GRASP55 or TGN46 was significantly dispersed with a higher punctum number in infected cells (Figure 5A-C, and 5F-H). However, different from all other Golgi markers tested above, both GRASP55 area and expression level were significantly reduced (Figure 5D-E), whereas both TGN46 area and expression level were dramatically increased after SARSCoV-2 infection (Figure 5I-J).

To further validate the immunofluorescence results, we infected Huh7-ACE2 and Vero E6 cells with SARS-CoV-2 and blotted for key Golgi structural and functional proteins as well as a number of proteins in endosomes, lysosomes, and autophagosomes. Consistent with our immunofluorescence results, GRASP55 down-regulation and TGN46 up-regulation induced by SARS-CoV-2 infection were observed in both cell lines (Figure 5K, L, and N; Figure S6K, L, and N), while GRASP65 expression was not altered (Figure 5M; Figure S6M). SARS-CoV-2 infection also increased the precursor and total CatD level and elevated the LC3-II/LC3-I ratio while showing no impact on the expression of EEA1, GPP130, and ERGIC-53 (Figure 5O-S). Given that the infection rate was well below $100 \%$, the actual changes were expected to be stronger than observed on the western blots. Taken together, GRASP55 was down-regulated and TGN46 was up-regulated by SARS-CoV-2 infection, suggesting that GRASP55 and TGN46 could serve as potential targets to interfere with SARS-CoV-2 infection.

\section{GRASP55 expression significantly reduces SARS-CoV-2 infection}

To test whether GRASP55 is a target of SARS-CoV-2 infection, we expressed GFP, GFP-tagged wild-type GRASP55, and the oligomerization domain of GRASP55 (GRASP55 N) in Huh7-ACE2 cells prior to SARS-CoV-2 infection. Interestingly, cells that express GRASP55 or GRASP55 N displayed a significantly lower viral infection rate compared to cells that express GFP (Figure 6A-B). 
Previously we have shown that disruption of the stacked Golgi structure by depletion of GRASP55 and GRASP65 accelerates intra-Golgi trafficking possibly by increasing the membrane surface for vesicle formation (Xiang et al., 2013). This suggests a possibility that SARS-CoV-2 may utilize a similar mechanism to facilitate viral trafficking. To test whether GRASP55 expression affects spike protein trafficking, we co-expressed GRASP55 or GFP with spike and performed a cell surface biotinylation assay to compare the amount of spike protein at the plasma membrane. Much less spike was detected at the cell surface in GRASP55-expressing cells compared to GFP-expressing cells (Figure 6C, lane 8 vs. 7), although the total spike expression levels were comparable. This strongly suggests that GRASP55 expression hinders spike protein trafficking. Consistently, GRASP55 expression also reduced ACE2 protein level at the cell surface, while this effect was enhanced by spike expression (Figure 6C). A similar effect was observed for transferrin receptor (TfR), another protein at the surface (Figure 6C). Based on these results, we propose a working model to explain the novel role of GRASP55 in SARS-CoV-2 trafficking (Figure 6D). Under normal conditions, GRASP55 is highly expressed, and the Golgi apparatus forms a stacked structure. SARS-CoV-2 infection decreases GRASP55 expression, resulting in Golgi fragmentation that may facilitate viral trafficking. When GRASP55 is exogenously expressed, the SARS-CoV-2 trafficking is reduced, thus limiting viral secretion and spread.

\section{TGN46 is required for viral trafficking of both WA-1 and Delta variants of SARS-CoV-2}

The fact that TGN46 protein level is significantly increased in SARS-CoV-2 infected cells indicates a need for TGN46 in viral infection. Therefore, we speculated that depletion of TGN46 would most likely inhibit SARS-CoV-2 infection. Indeed, when TGN46 was depleted, the infection rate of SARS-CoV-2 USA-WA1 strain was significantly reduced (Figure 7A-B). To determine if this effect is specific for the WA1 strain, we also tested the Delta variant. Similar to the WA1 strain, TGN46 knockdown also largely reduced the infection rate of the Delta variant (Figure 7C-D). These results demonstrate an essential role of TGN46 in SARS-CoV-2 infection independent of the viral strain.

To confirm the role of TGN46 in SARS-CoV-2 infection using an alternative approach, we infected control and TGN46-depleted cells by SARS-CoV-2 and determined the expression level of viral proteins in cells by western blotting. Consistent with the viral infection assays, the immunoblotting results showed that depletion of TGN46 reduced the expression of both spike and nucleocapsid viral proteins when cells were infected with either the USA-WA1 strain or the Delta variant, confirming a critical role of TGN46 in SARS-CoV-2 infection with both strains (Figure 7E). 
Given that TGN46 is recycling between the Golgi and plasma membrane, we speculated that it may facilitate viral trafficking from the Golgi to the plasma membrane. To test the role of TGN46 in viral trafficking, we transfected control and TGN46-depleted Huh7-ACE2 cells with spike and performed cell surface biotinylation and streptavidin pulldown. The amount of spike protein at the cell surface was dramatically decreased after TGN46 depletion, which was revealed by both strep and spike antibodies (Figure 7F, lane 8 vs. 7). In spike expressing cells, not only spike was affected by TGN46 knockdown, several other cell surface proteins, including ACE2, insulin-like growth factor 2 receptor (IGF2R), TfR, and E-cadherin, all displayed a reduction at the plasma membrane in TGN46 knockdown cells (Figure 7F, lane 8 vs. 7). The effect of TGN46 knockdown on ACE2, IGF2R and TfR cell surface localization was not detected in non-spike expressing cells (Figure 7F, lane 6 vs. 5), implying that spike expression or viral infection may hijack the majority of TGN46 for viral trafficking and so post-Golgi trafficking of many cell receptors to the plasma membrane is impeded. Consistently, the level of TGN46 at the cell surface was increased after spike expression, indicating that TGN46 may recycle more frequently between the trans-Golgi network (TGN) and the plasma membrane when spike is expressed. The level of LAMP1 at the cell surface was also increased after spike expression (Figure 7F, lane 7 vs. 5), consistent with the previous report that SARS-CoV-2 infection enhances lysosomal exocytosis (Ghosh et al., 2020).

To further test the role of TGN46 in Golgi-to-plasma membrane trafficking, we performed a VSV-G trafficking assay using the RUSH system (Boncompain et al., 2012). We first transfected control and TGN46-depleted cells with the Str-Ii_VSV-G-SBP-EGFP plasmid (Ireland et al., 2020a), and released VSV-G with biotin at $20^{\circ} \mathrm{C}$ to accumulate VSV-G in the TGN (Matlin and Simons, 1983). We then shifted the cells to $37^{\circ} \mathrm{C}$ to release VSV-G from the TGN and measured its level at the plasma membrane by cell surface staining. As shown in Figure S7, TGN46 knockdown significantly reduced VSV-G trafficking from the TGN to the plasma membrane. Taken together, we propose a working model of TGN46 in SARS-CoV-2 trafficking (Figure 7G). In brief, SARS-CoV-2 infection significantly increases TGN46 protein level to accelerate viral trafficking, whereas TGN46 depletion inhibits the trafficking and release of all variants of SARS-CoV-2. Our study revealed TGN46 as a promising target for COVID-19 treatment.

\section{Discussion}

In this study, we revealed that SARS-CoV-2 infection triggers a global change of the endomembrane 
system in host cells, in particular the Golgi structure (Table 1). Significantly, disrupting the Golgi function with small molecules strongly inhibits viral infection. Furthermore, expression of individual SARS-CoV-2 viral proteins (S, M, E, or ORF3a) is sufficient to trigger Golgi fragmentation. To determine the mechanism of Golgi fragmentation induced by SARS-CoV-2 infection, we surveyed a large number of Golgi proteins in SARS-CoV-2 infected cells. While several Golgi proteins are impacted by viral infection, GRASP55 and TGN46 are the top two proteins whose levels changed most dramatically in opposite trends. Finally, we showed that overexpression of GRASP55 strongly inhibits SARS-CoV-2 infection and trafficking, whereas knockdown of TGN46 displayed the same effects. Thus, our study uncovers a novel mechanism by which SARS-CoV-2 modulates the Golgi structure via regulating GRASP55 and TGN46 expression to facilitate viral trafficking (Figure 6D; Figure 7G). Our results indicate that the Golgi apparatus may serve as a novel therapeutical target for the treatment of COVID-19 and other diseases caused by viruses that utilize a similar trafficking pathway.

The Golgi stacking proteins, GRASP55 and GRASP65, play essential roles in Golgi structure formation (Tang and Wang, 2013; Xiang and Wang, 2010) by forming trans-oligomers that "glue" adjacent Golgi cisternae together into stacks and ribbon (Tang et al., 2012; Tang et al., 2010b). Expression of phospho-deficient mutants of GRASPs (e.g., the GRASP domain of GRASP55 or GRASP55 N) at least partially inhibits mitotic Golgi disassembly (Wang et al., 2005; Xiang and Wang, 2010). Inhibition of Golgi stacking in cells by microinjecting GRASP antibodies or by GRASP55/65 knockdown/knockout (KD/KO) (Tang et al., 2010b; Wang et al., 2003) accelerates protein trafficking but impairs accurate glycosylation and sorting (Bekier et al., 2017; Wang et al., 2008; Xiang et al., 2013), increases heparan sulfate but decreases chondroitin sulfate synthesis (Ahat et al., 2022), and disrupts other cellular activities such as cell attachment, migration, and growth (Ahat et al., 2019). A plausible explanation is that stacking may reduce the accessibility of coat proteins to Golgi membranes, which decreases the rate of vesicle budding and fusion (Huang and Wang, 2017; Zhang and Wang, 2015, 2016). Therefore, it is reasonable to speculate that Golgi fragmentation observed in this study may facilitate SARS-CoV-2 trafficking and release.

SARS-CoV-2 infection down-regulates GRASP55 but not its homolog GRASP65. GRASP55 has been shown to play a crucial role in various stress responses (Ireland et al., 2020b; Nüchel et al., 2021; Zhang and Wang, 2018, 2020), while GRASP65 functions more in cell migration and apoptosis (Ahat et al., 2019; Bisel et al., 2008; Lane et al., 2002). In this study, we found that GRASP55 plays a vital role in viral infection, most likely related to its function in Golgi structure 
formation. Indeed, expression of GRASP55 significantly inhibited spike protein trafficking to the cell surface (Figure 6C), supporting our hypothesis that SARS-CoV-2 induced GRASP55 downregulation facilitates viral trafficking, which is also consistent with the previous finding that GRASP55-depletion induced Golgi structural defect enhances protein trafficking (Xiang et al., 2013). On the other hand, GRASP55 expression decreased the cell surface localization of ACE2 (Figure 6C), suggesting that GRASP55 may also play a role in the SARS-CoV-2 cell entry pathway. Therefore, our study reveals GRASP55 as an important target that can be manipulated in order to control SARA-CoV-2 infection and spread.

Since TGN46 is a glycoprotein that recycles between the TGN and cell surface (Ponnambalam et al., 1994; Reaves et al., 1993), we postulate that the increased TGN46 level indicates a need for TGN46 to satisfy the high flux of virion trafficking through the late secretory pathway, and our results support this hypothesis. Notably, while depletion of TGN46 inhibited spike protein trafficking, the amount of ACE2 at the cell surface was unaffected upon knocking down TGN46 alone without spike protein expression, which is different from GRASP55 expression assay. These observations indicate that TGN46 functions in the post-Golgi trafficking of the SARS-CoV-2 virus. Our discoveries that SARS-CoV-2 reduces GRASP55 and elevates TGN46 expression are also supported by a number of RNA-seq and proteomic studies of SARS-CoV-2 infected cells and human tissues (Blanco-Melo et al., 2020; Bojkova et al., 2020; Sun et al., 2020). Significantly, our results demonstrate that either overexpression of GRASP55 or depletion of TGN46 significantly inhibits SARS-CoV-2 infection (Figure 6 and Figure 7).

While it has been shown that CQ does not block SARS-CoV-2 infection in the human lung cell line Calu-3 (Hoffmann et al., 2020b), it does greatly reduce viral infection in Huh7-ACE2 cells in our study. This inconsistency can be explained by that SARS-CoV-2 entry into Calu-3 cells is independent of endosomal acidification because of its high expression level of TMPRSS2, which activates spike at the plasma membrane; while the Huh7.5 (a derivative cell line of Huh7) cells heavily rely on the endosomal low pH for SARS-CoV-2 entry (Dittmar et al., 2021), resulting in a high dependence on lysosomes whose function can be inhibited by CQ. Vacuolin-1 is sometimes regarded as a lysosomal exocytosis inhibitor, but it has also been reported to alter the morphology of lysosomes without inhibiting $\mathrm{Ca}^{2+}$-regulated lysosomal exocytosis (Huynh and Andrews, 2005). Thus, it is unclear whether the inhibition of SARS-CoV-2 infection by vacuolin-1 observed in our study is due to the inhibition of SARS-CoV-2 release via lysosomal exocytosis. While the molecular mechanism and route by which the SARS-CoV-2 virus moves from the Golgi to the extracellular 
bioRxiv preprint doi: https://doi.org/10.1101/2022.03.04.483074; this version posted March 7. 2022. The copyright holder for this preprint (which was not certified by peer review) is the author/funder, who has granted bioRxiv a license to display the preprint in perpetuity. It is made available under aCC-BY-NC-ND 4.0 International license.

space remain largely unknown, the identification of GRASP55 and TGN46 in this process will help address these important and open questions. 


\section{Methods and Materials}

\section{Generation of cDNA constructs}

All pCAG plasmids encoding Flag-tagged SARS-CoV-2 proteins were constructed as described (Zhang et al., 2020). All pCAG plasmids encoding Strep-tagged SARS-CoV-2 proteins were kind gifts from Dr. Nevan Krogan (Gordon et al., 2020). The Str-Ii_VSV-G-SBP-EGFP plasmid was provided by Franck Perez (Institut Curie). The pEGFP-N1, pEGFP-N1-GRASP55, pEGFP-N1GRASP55 N domain, and pEGFP-N1-GRASP65 plasmids were laboratory products (Xiang and Wang, 2010; Zhang et al., 2018).

\section{Cell culture and transfection}

ACE2-expressing Huh7 cells were sorted, enriched, and selected by flow cytometry (FACS) to guarantee a high infection rate of SARS-CoV-2 (Sherman et al., 2021). Huh7-ACE2 and Vero E6 (ATCC CRL 1586) cells were cultured in Dulbecco's Modified Eagle’s Medium (Gibco) supplemented with 10\% fetal bovine serum (FBS, Hyclone), 100 units $/ \mathrm{ml}$ penicillin and $100 \mu \mathrm{g} / \mathrm{ml}$ streptomycin (Invitrogen) at $37^{\circ} \mathrm{C}$ with $5 \% \mathrm{CO}_{2}$. Plasmid transfection was performed using Lipofectamine 2000 or Lipofectamine 3000 (Invitrogen) following the manufacturer's instructions. After 24-48 h, transfected cells were fixed by 4\% paraformaldehyde (PFA) for immunofluorescence analysis or were lysed in IGEPAL-C360 lysis buffer $(20 \mathrm{mM}$ Tris $\mathrm{HCl} \mathrm{pH} 8.1,37 \mathrm{mM} \mathrm{NaCl}, 1 \%$ IGEPAL-C360, 10\% glycerol, 2 mM EDTA supplemented with protease inhibitor cocktail from Thermo Fisher) for immunoblotting.

\section{SARS-CoV-2 viral strains and amplification}

Most experiments were conducted using SARS-CoV-2, Isolate USA-WA1/2020 (BEI NR-52281), unless specified. The Delta variant of SARS-CoV-2 used in the study is the Isolate hCoV19/USA/PHC658/2021 (Lineage B.1.617.2; BEI NR-55611). SARS-CoV-2 working stocks were amplified by infecting Vero E6 cells in 2\% FBS DMEM and $182 \mathrm{~cm}^{2}$ flasks with $70-80 \%$ confluency. Flasks were incubated until cytopathic effect (CPE) became distinctly visible, generally at 3-4 days post-infection (dpi). The supernatant was harvested, filtered through $0.45 \mu \mathrm{m} \mathrm{SCFA}$ syringe filters and pipetted into $500 \mu \mathrm{l}$ aliquots, with tubes of viral stock then being stored at $-80^{\circ} \mathrm{C}$. One vial of each propagated stock was thawed after $24 \mathrm{~h}$ and titered by TCID50, with positive wells determined by the presence of CPE 3 dpi observed by 200x objective phase-contrast microscopy. Viral titer was calculated by the modified Reed and Muench method. All live SARS-CoV-2 work was performed in an approved BSL3 facility at the University of Michigan. 


\section{RNA interference}

siRNA Universal Negative Control \#1 (siControl), siGRASP55 with 5'-

UGAUAACUGUCGAGAAGUGAUUAUU-3' sequence, siGRASP65 with 5'CCUGAAGGCACUACUGAAAGCCAAU-3' sequence, and siTGN46 with 5'CCACCGAAAGCGUCAAGCAAGAAGA-3' sequence were obtained from Sigma-Aldrich. Huh7ACE2 cells were transfected with siRNA oligos (final concentration, $50 \mathrm{nM}$ ) by RNAi-MAX (Invitrogen) on day 1 and infected with SARS-CoV-2 on day 3. Cells were fixed by 4\% PFA on day 4 for immunofluorescence analysis.

\section{Immunoblotting}

Huh7-ACE2 or Vero E6 cells were seeded onto 6-well plates on day 1 and incubated with or without SARS-CoV-2 (MOI = 2) on day 2 for 24 h. Cells were lysed in IGEPAL-C360 lysis buffer. For regular immunoblotting of uninfected cells, cells were lysed in lysis buffer (20 mM Tris-HCl pH 8.0, $150 \mathrm{mM} \mathrm{NaCl}, 1 \%$ Triton X-100 supplemented with protease inhibitor cocktail (Thermo Fisher). The homogenate was centrifuged at $13000 \times g$ for 15 min to remove cell debris, then denatured at $95^{\circ} \mathrm{C}$ for $10 \mathrm{~min}$ in 2x Laemmli buffer supplemented with 5\% 2-mercaptoethanol. Protein quantification was performed using a Bradford Kit (Bio-Rad). Protein samples were analyzed by SDS-PAGE and then transferred to nitrocellulose membranes using a semi-dry or wet transfer machine. The membranes were blocked in 5\% milk in PBST $(0.1 \%$ Tween 20 in phosphate buffered saline) and incubated with proper antibodies and visualized by a FluorChem $\mathrm{M}$ chemi-luminescent imager (ProteinSimple, San Jose, CA) with enhanced chemiluminescence (Thermo Fisher Scientific). The antibodies used in this study are shown in Supplementary Table 1.

\section{Immunofluorescence}

Huh7-ACE2 or Vero E6 cells were seeded on poly-lysine-coated coverslips. SARS-CoV-2 infected cells were fixed with 4\% paraformaldehyde (PFA) for $30 \mathrm{~min}$ for complete virus inactivation, which was validated, and the protocol was approved by the Institutional Biosafety Committee at University of Michigan. Cells were quenched with $50 \mathrm{mM} \mathrm{NH}_{4} \mathrm{Cl}$ in $\mathrm{PBS}$ for 10 min with gentle rocking and permeabilized with $0.2 \%$ Triton $\mathrm{X}-100$ for $10 \mathrm{~min}$. Cells were blocked with $0.2 \%$ gelatin blocking buffer in PBS (PGA) for 30 min at room temperature, incubated with primary antibodies overnight and secondary antibodies for $1 \mathrm{~h}$. The antibodies used for immunofluorescence were shown in Supplementary Table 1. Hoechst 33258 (Sigma-Aldrich) was used to stain the nuclear DNA. About 15 to 20 random images were taken for each independent experiment with a $60 \mathrm{x}$ oil objective on a 
Nikon ECLIPSE Ti2 Confocal microscope and processed with maximum intensity projection. Quantifications were performed to calculate item number, area, sum intensity of selected ROIs using the Nikon NIS-Elements AR analysis software. Control and virus-infected samples were processed in parallel following the same procedure. All images for the same marker were captured and processed with the same setting. For 3D video reconstruction, samples were prepared as above. Images were taken for totally 40 stacks with each step $0.15 \mu \mathrm{m}$ to collect as much continuous signal as possible. Maximum intensity projection was performed, and videos were made with the Nikon NIS-Elements AR analysis software.

\section{Viral infection rate assay}

Huh7-ACE2 cells were seeded onto poly-lysine-coated coverslips on day 1. On day 2, cells were treated with or without indicated molecules and immediately infected with SARS-CoV-2 for $24 \mathrm{~h}$. Cells were fixed with 4\% PFA for $30 \mathrm{~min}$ and processed for immunofluorescence analysis. Images were taken with a 20x air objective on a Nikon ECLIPSE Ti2 Confocal microscope and processed with maximum projection. Cell numbers for uninfected or infected cells were counted by the counting tool in Photoshop using nucleocapsid as a virus marker and the viral infection rate [infected cells/(uninfected + infected cells)] for DMSO treatment was normalized to $100 \%$.

\section{Cell surface biotinylation assay}

Cell surface biotinylation assay was performed as previously described (Ahat et al., 2019). All procedures were performed on ice or at $4^{\circ} \mathrm{C}$. In brief, Huh7-ACE2 cells were seeded on 15-cm dishes. After knocking down TGN46 or overexpression of GRASP55, cells were washed twice with ice-cold PBS, treated with $10 \mathrm{ml}$ of $0.5 \mathrm{mg} / \mathrm{ml} \mathrm{NHS-SS-biotin} \mathrm{(Thermo} \mathrm{Fisher)} \mathrm{in} \mathrm{PBS} \mathrm{for} 20$ min in the cold room, and quenched by $100 \mathrm{mM}$ glycine in PBS for $10 \mathrm{~min}$. After three washes with icecold PBS, cells were lysed in RIPA buffer (20 mM Tris-HCl, pH 8.0, $150 \mathrm{mM} \mathrm{NaCl,1 \%}$ Triton X100, $0.1 \%$ SDS, $0.1 \%$ sodium deoxycholate, $1 \mathrm{mM}$ EDTA, $50 \mathrm{mM}$ sodium fluoride, $20 \mathrm{mM}$ sodium orthovanadate, and $1 \times$ protease inhibitor cocktail). After centrifugation, the supernatants were adjusted to the same concentration and incubated with streptavidin-agarose beads overnight. After extensive wash, beads were boiled in SDS loading buffer with $40 \mathrm{mM}$ DTT. Proteins were separated by SDS-PAGE and analyzed by immunoblotting.

\section{VSV-G trafficking assay}

Huh7-ACE2 cells were seeded onto poly-lysine coated coverslips in 6-well plates at the density of 
60,000 cells/ml on Day 1. Cells were transfected with siTGN46 oligos using RNAi-MAX on Day 2 and the Str-Ii_VSV-G-SBP-EGFP plasmid using Lipofectamine 3000 on Day 4. On day 5, cells were treated with $40 \mu \mathrm{M}$ biotin in culture medium at $20^{\circ} \mathrm{C}$ for $2 \mathrm{~h}$ to accumulate VSV-G in the TGN. Cells were transferred to the incubator at $37^{\circ} \mathrm{C}$ to release the VSV-G protein for 0,30 , and $60 \mathrm{~min}$. Immediately, cells were rinsed with chilled PBS and incubated with a primary VSV-G antibody that recognizes its luminal domain for $90 \mathrm{~min}$ in culture medium on ice. After rinsing with chilled PBS, cells were fixed in chilled 4\% PFA for 15 min, washed twice with PBS, and incubated with PGA for $30 \mathrm{~min}$. Cells were incubated with appropriate secondary antibody for $1 \mathrm{~h}$ at room temperature and stained with Hoechst 33258 for 5 min. Cells were rinsed, mounted, and imaged on a Nikon ECLIPSE Ti2 Confocal microscope. Quantification was performed using the Nikon analysis software to calculate the relative ratio of surface VSV-G/total VSV-G from three independent experiments.

\section{Electron microscopy (EM)}

All EM-related reagents were purchased from Electron Microscopy Sciences (EMS; Hatfield, PA). Huh7-ACE2 cells were infected with or without SARS-CoV-2 $(\mathrm{MOI}=1)$ for $24 \mathrm{~h}$ and fixed in 2\% glutaraldehyde at room temperature for $30 \mathrm{~min}$. Cells were washed three times with $0.1 \mathrm{M}$ sodium cacodylate, and post-fixed on ice in $1 \%$ (wt/vol) reduced osmium tetroxide, $0.1 \mathrm{M}$ sodium cacodylate and $1.5 \%$ (wt/vol) cyanoferrate. Cells were rinsed 3 times with $0.1 \mathrm{M}$ sodium cacodylate and 3 times with water, and processed for successive dehydration and embedding as previously described (Tang et al., 2010a). Resin blocks were cut to ultrathin $(50-70 \mathrm{~nm})$ sections with a diamond knife and mounted on Formvar-coated copper grids. Grids were double contrasted with $2 \%$ uranyl acetate for 5 min and then with lead citrate for 2 min and washed with excess water. Images were captured at 1,500x, 3,000x, 8,000x, and 12,000x magnifications by a JEOL JEM-1400 transmission electron microscope.

\section{Quantitation and statistics}

All data represent the mean \pm SEM of at least three independent experiments unless noted. Statistical analyses were performed by two-tailed Student's t-test or one-way ANOVA, Tukey's multiple comparison test using Origin7. Differences in means were considered as no statistical significance (n.s.) if $\mathrm{p} \geq 0.05$. Significance levels are as follows: ${ }^{*}, \mathrm{p}<0.05 ; * *, \mathrm{p}<0.01 ; * * *, \mathrm{p}<0.001$. Figures are assembled with Photoshop CS6 Extended (Adobe, San Jose, CA). Figure 6C and Figure 7G are created with BioRender. 


\section{ACKNOWLEDGMENTS}

We thank Dr. Nevan Krogan for kind gifts of plasmids encoding Strep-tagged SARS-CoV-2 proteins; Drs. Zhe Han, Jin-Gu Lee, Weichao Zhang, Ming Li, Haoxing Xu, and Meiqin Hu for reagents; and Dr. Gregg Sobocinski for technical assistance on electron microscopy. We thank current and past members of the Wang lab, especially Jie Li and Sevval Ercan, for stimulating discussions and suggestions. This work was supported by the National Institutes of Health (Grants R35GM130331 and R01NS102279) and the Fast Forward Protein Folding Disease Initiative of the University of Michigan to Y. Wang.

\section{AUTHOR CONTRIBUTIONS}

J.Z., A.W.T, and Y.W. designed the experiments. A.K. performed all the viral infection and fixation of viral-infected cells. J.Z. prepared IF and EM samples. J.Z., W.R., J.J., L.X., and M.R. performed microscopy imaging and quantification. L.X. and J.Z. performed EM imaging. S.B. and J.Z. performed immunoblotting of infected cells. E.A. prepared samples of viral protein expressed cells and S.B. immunoblotted the samples. L.X. and J.Z. performed the cell surface biotinylation assay. Q.T. made the constructs of Flag-tagged viral proteins. J.Z. and Y.W. analyzed the data and wrote the paper.

\section{DECLARATION OF INTERESTS}

The authors declare no competing interests. 
Figures and Legends
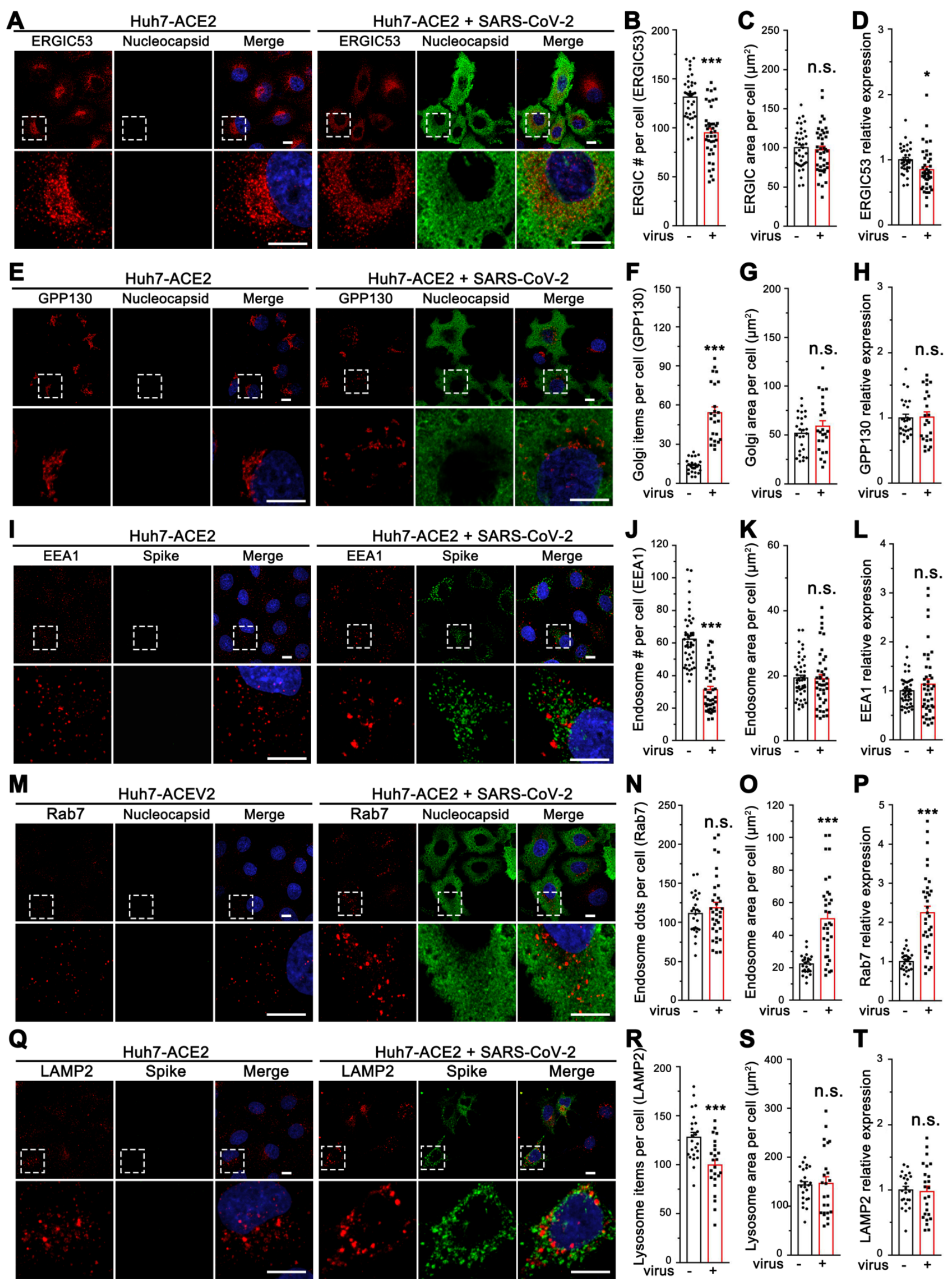
Figure 1. SARS-CoV-2 infection induces global morphological changes of host cell membrane organelles.

(A) Representative confocal images of Huh7-ACE2 cells incubated with or without SARS-CoV-2 $(\mathrm{MOI}=1)$ for $24 \mathrm{~h}$ and stained for ERGIC53 and nucleocapsid.

(B-D) Quantification of ERGIC53 for the number of puncta (B), area (C), and relative expression (D) in A.

(E) Representative confocal images of Huh7-ACE2 cells incubated with or without SARS-CoV-2 $(\mathrm{MOI}=1)$ for $24 \mathrm{~h}$ and stained for a cis-Golgi marker GPP130 and nucleocapsid.

(F-H) Quantification of GPP130 item number (F), area $(\mathrm{G})$, and relative expression $(\mathrm{H})$ in E.

(I) Representative confocal images of Huh7-ACE2 cells incubated with or without SARS-CoV-2 $(\mathrm{MOI}=1)$ for $24 \mathrm{~h}$ and stained for an early endosome marker EEA1 and spike.

(J-L) Quantification of EEA1 item number $(\mathrm{J})$, area $(\mathrm{K})$, and relative expression (L) in I.

(M) Representative confocal images of Huh7-ACE2 cells incubated with or without SARS-CoV-2 $(\mathrm{MOI}=1)$ for $24 \mathrm{~h}$ and stained for a late endosome marker Rab7 and nucleocapsid.

(N-P) Quantification of Rab7 in M.

(Q) Representative confocal images of Huh7-ACE2 cells incubated with or without SARS-CoV-2 $(\mathrm{MOI}=1)$ for $24 \mathrm{~h}$ and stained for a late endosome/lysosome marker LAMP2 and spike.

(R-T) Quantification of Rab7 in Q.

Boxed areas in the upper panels are enlarged and shown underneath. Scale bars in all panels, $10 \mu \mathrm{m}$. All quantitation data are shown as mean \pm SEM from three independent experiments. Statistical analyses are performed using two-tailed Student's t-test. *, p $<0.05 ;{ }^{* *}, \mathrm{p}<0.01 ; * * *, \mathrm{p}<0.001$; n.s., no significance. 

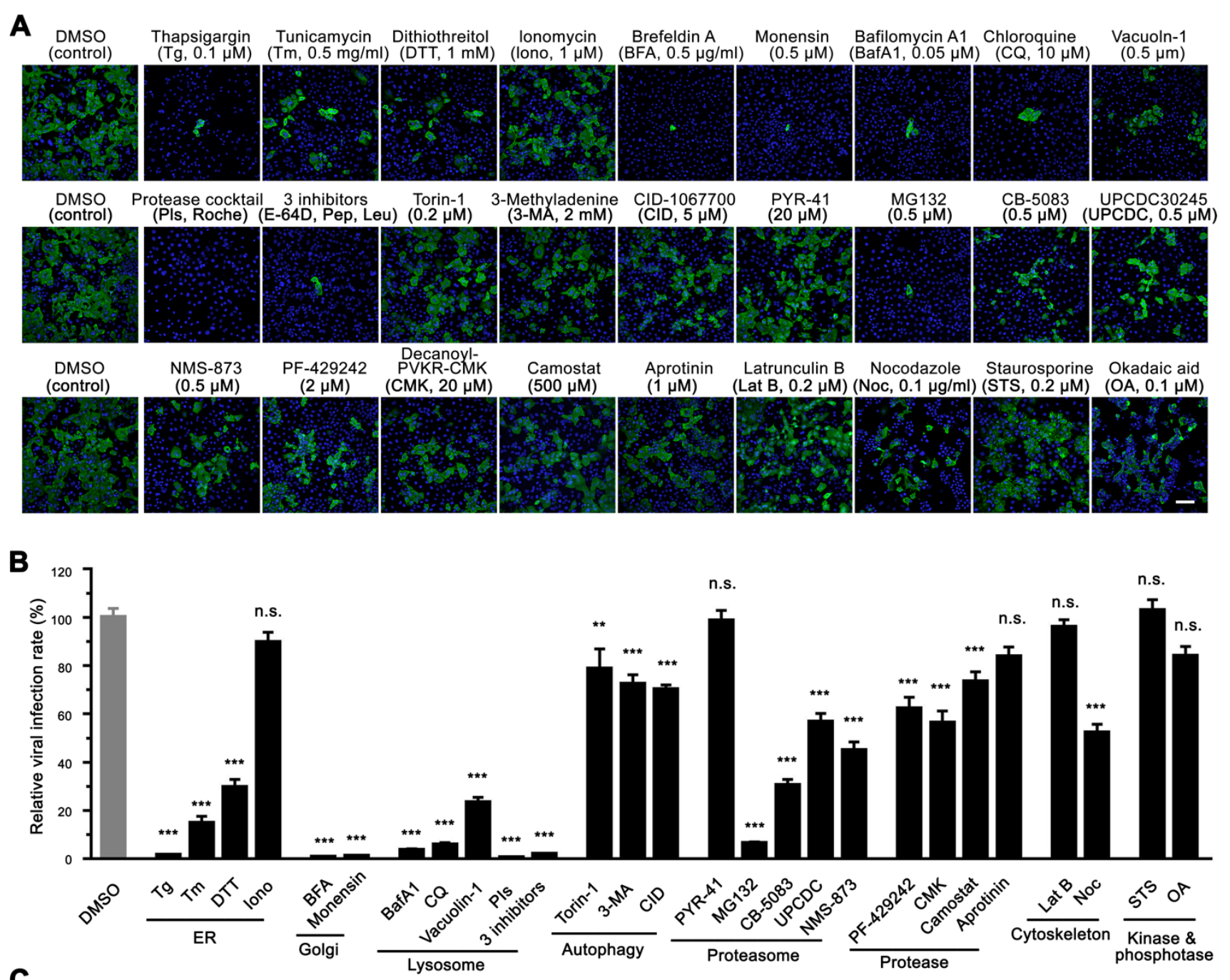

C

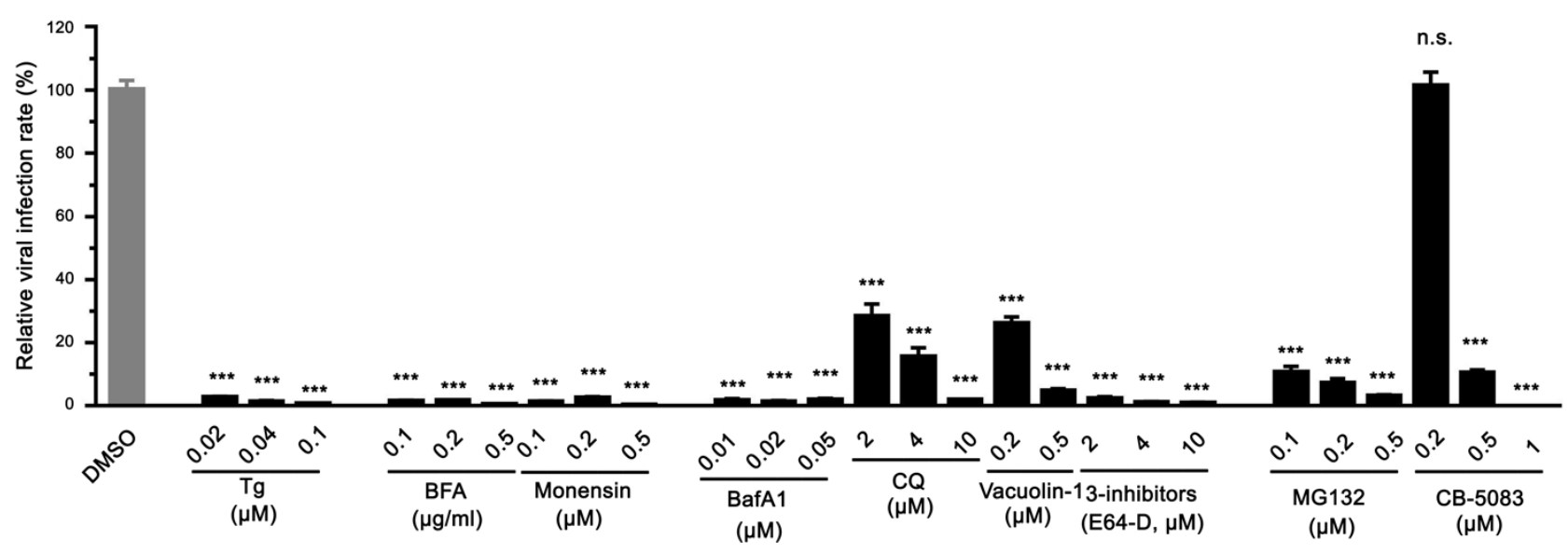

Figure 2. Chemicals disrupting Golgi functions inhibit SARS-CoV-2 infection.

(A) Representative immunofluorescence images of Huh7-ACE2 cells infected with SARS-CoV-2 $(\mathrm{MOI}=1)$ for $24 \mathrm{~h}$ in the presence of indicated chemicals and stained for nucleocapsid and DNA.

The concentrations of the chemical are shown in the figure or as follows: protease inhibitor cocktails (PIs), $100 \mathrm{ml} /$ tablet; 3 inhibitors, $10 \mu \mathrm{M}$ E-64D, $20 \mu \mathrm{M}$ pepstatin, $100 \mu \mathrm{M}$ leupeptin.

Scale bar, $100 \mu \mathrm{m}$. 
(B) Quantification of the viral infection rate in A, with the control normalized to $100 \%$. Data are shown as mean \pm SEM from 20-30 random images from two or three independent experiments.

(C) Quantification of the viral infection rate in the presence of indicated chemicals with different concentrations (images are shown in Figure S3), with the control normalized to 100\%. Data are shown as mean \pm SEM from 10 representative images.

Statistical analyses are performed using one-way ANOVA, Tukey's multiple comparison test. *, p < $0.05 ; * * *, p<0.001 ;$ n.s., no significance. 

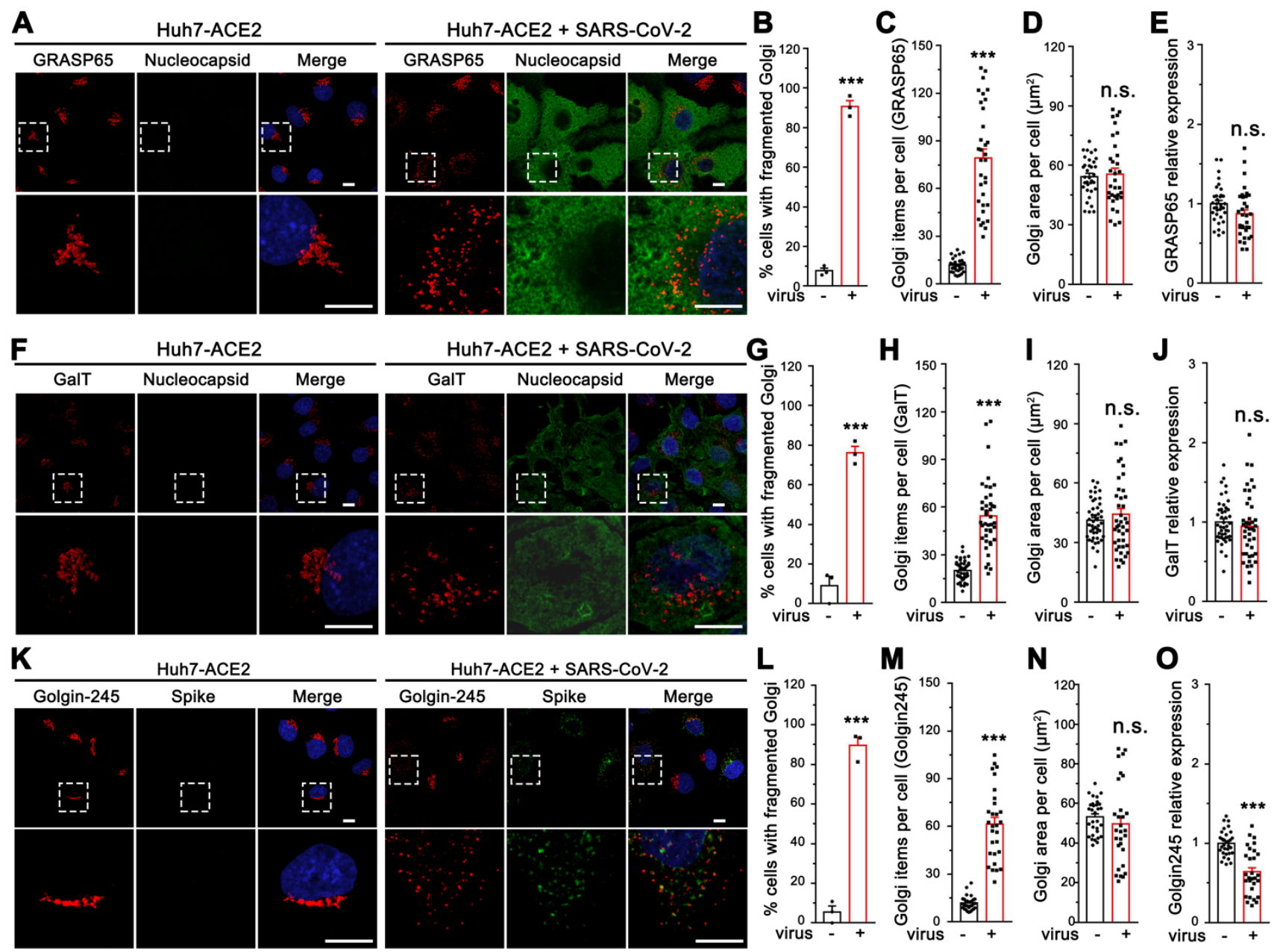

$\mathbf{P}$

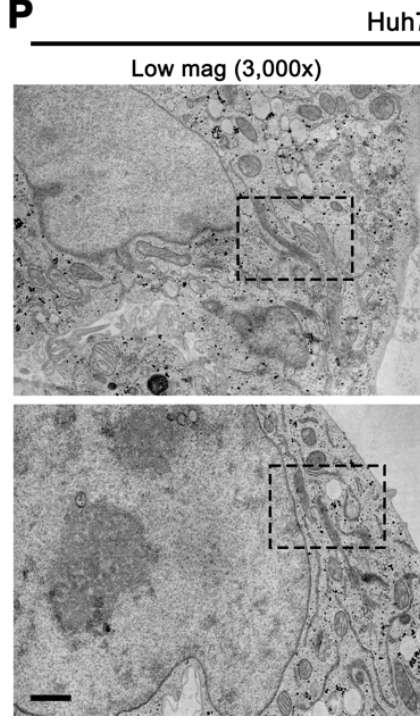

Huh7-ACE2
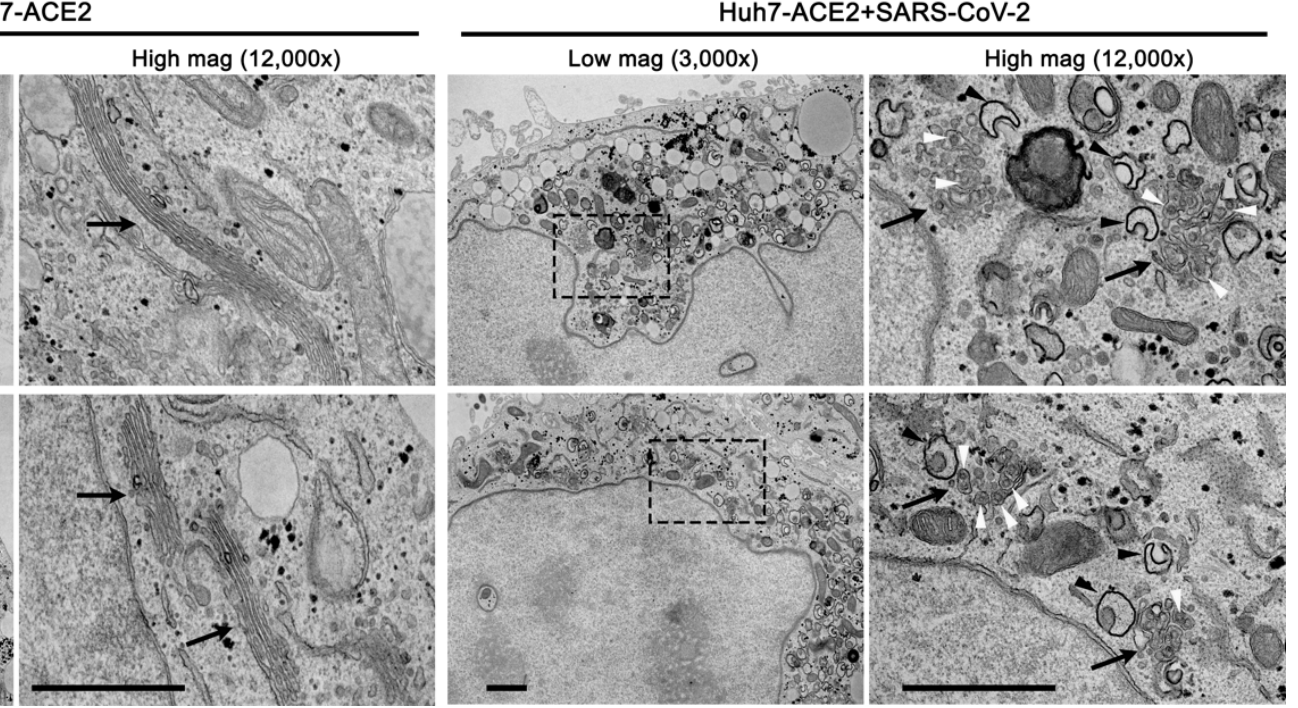

Figure 3. SARS-CoV-2 infection dramatically disrupts the Golgi structure.

(A) Representative confocal images of Huh7-ACE2 cells incubated with or without SARS-CoV-2

$(\mathrm{MOI}=1)$ for $24 \mathrm{~h}$ and stained for a cis-Golgi marker GRASP65 and nucleocapsid.

(B-E) Quantification of A for the percentage of cells with fragmented Golgi (B), GRASP65 punctum number (C), area (D), and relative expression level (E). 
(F) Representative confocal images of Huh7-ACE2 cells incubated with or without SARS-CoV-2 $(\mathrm{MOI}=1)$ for $24 \mathrm{~h}$ and stained for a trans-Golgi marker GalT and nucleocapsid.

(G-J) Quantification of GalT in F.

(K) Representative confocal images of Huh7-ACE2 cells incubated with or without SARS-CoV-2 $(\mathrm{MOI}=1)$ for $24 \mathrm{~h}$ and stained for a TGN marker Golgin-245 and spike. Boxed areas in the upper panels of A, F and K are enlarged and shown underneath. Scale bars in all fluorescence images, $10 \mu \mathrm{m}$.

(L-O) Quantification of Golgin-245 in K. Quantitation data are shown as mean \pm SEM from three independent experiments. Statistical analyses are performed using two-tailed Student's t-test. *, p $<0.05 ; * *, \mathrm{p}<0.01 ; * * *, \mathrm{p}<0.001$; n.s., no significance.

(P) Electron micrographs of Huh7-ACE2 incubated with or without SARS-CoV-2 (MOI = 1) for $24 \mathrm{~h}$ under two different magnifications. Boxed areas on the left images are enlarged on the right. Black arrows, white arrowheads, and black arrowheads indicate Golgi membranes, viral particles, and DMVs. Scale bars, $500 \mathrm{~nm}$. 


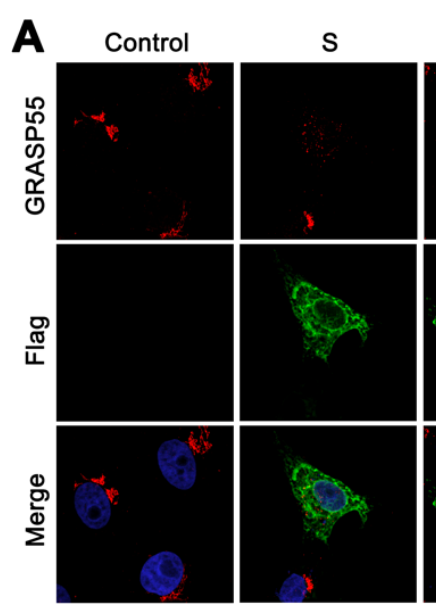

B

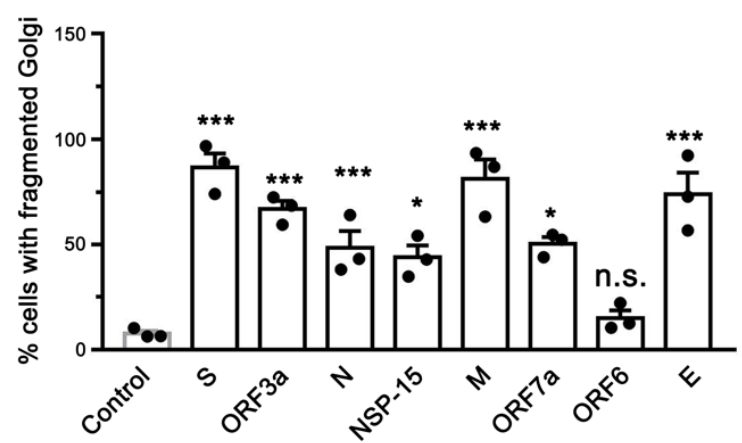

C

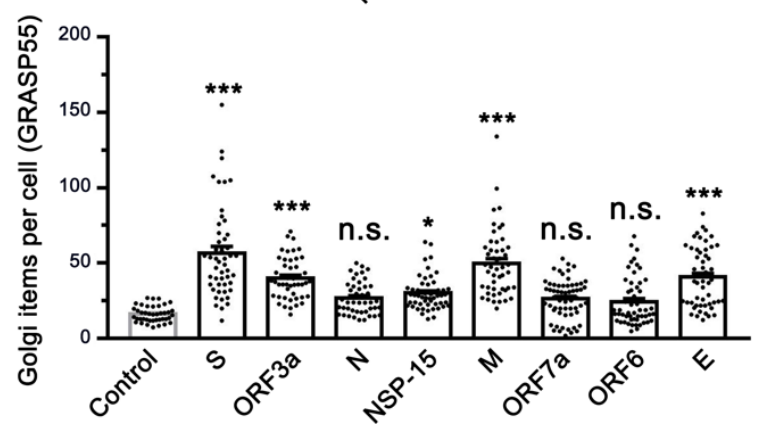

NSP-15
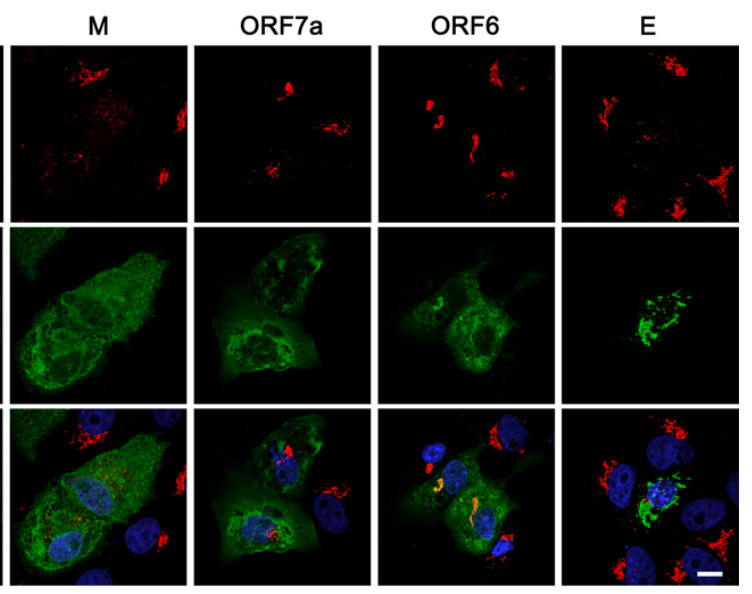

D

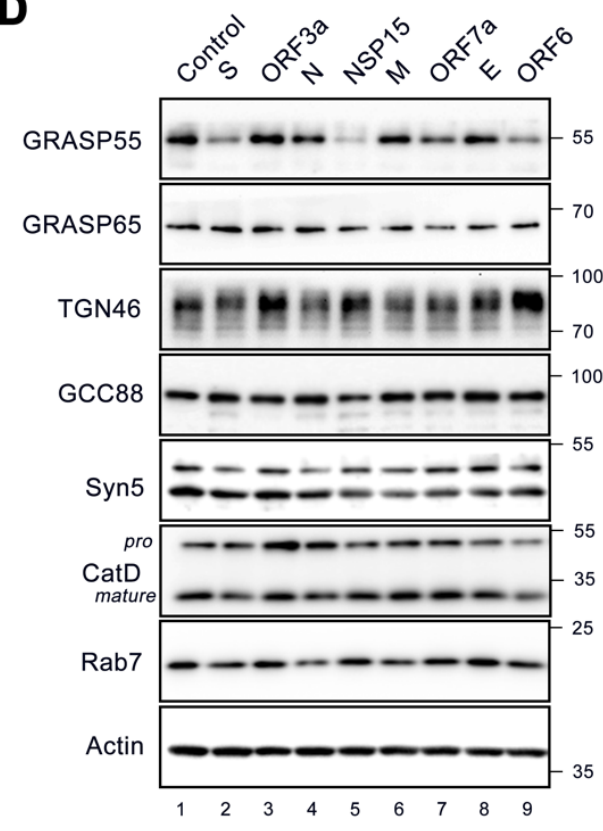

Figure 4. Expression of SARS-CoV-2 proteins triggers Golgi fragmentation.

(A) Representative confocal images of Vero E6 cells transfected with indicated Flag-tagged SARS-

CoV-2 proteins for $24 \mathrm{~h}$ and stained for GRASP55 and Flag. Scale bar, $10 \mu \mathrm{m}$.

(B-C) Quantification of A for the percentage of cells with fragmented Golgi (B) and GRASP55 item numbers $(\mathrm{C})$.

(D) Immunoblots of indicated proteins in Vero E6 cells transfected with indicated Strep-tagged

SARS-CoV-2 proteins for $24 \mathrm{~h}$. Protein expression level of all viral proteins is shown in Figure

S5. For Cathepsin D (CatD), the pro- and mature forms are indicated. 

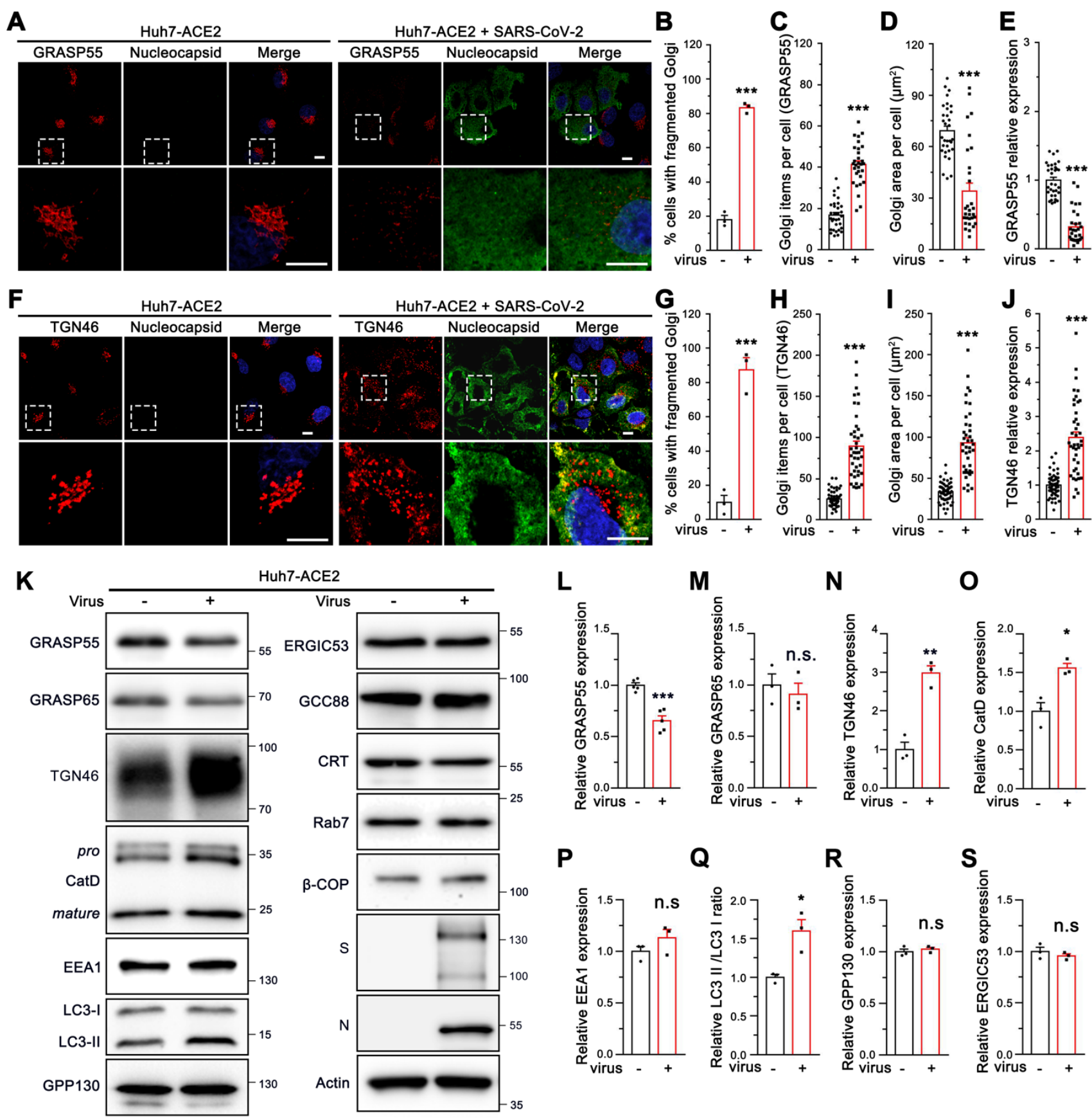

Q

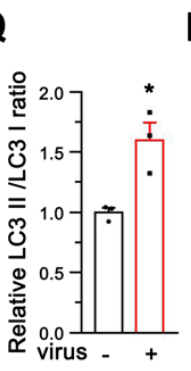

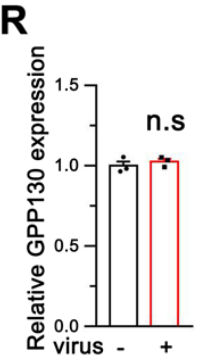

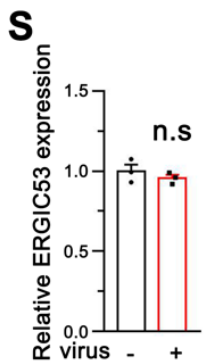

Figure 5. SARS-CoV-2 down-regulates GRASP55 and up-regulates TGN46 expression in

\section{Huh7-ACE2 cells.}

(A) SARS-CoV-2 infection reduces GRASP55 expression. Representative confocal images of Huh7ACE2 cells incubated with or without SARS-CoV-2 $(\mathrm{MOI}=1)$ for $24 \mathrm{~h}$ and stained for GRASP55 and nucleocapsid.

(B-E) Quantification of the percentage of cells with fragmented Golgi (B), GRASP55 item number (C), area (D), and relative expression level (E) in A.

(F) SARS-CoV-2 infection increases TGN46 expression. Representative confocal images of Huh7ACE2 cells incubated with or without SARS-CoV-2 $(\mathrm{MOI}=1)$ for $24 \mathrm{~h}$ and stained for TGN46 
and nucleocapsid. Boxed areas in the upper panels of A and F are enlarged and shown underneath. Scale bars, $10 \mu \mathrm{m}$.

(G-J) Quantification of the percentage of cells with fragmented Golgi (G), TGN46 item number (H), area (I), and relative expression level ( $\mathrm{J})$ in F.

(K) Immunoblots of Huh7-ACE2 cells incubated with or without SARS-CoV-2 (MOI = 2) for $24 \mathrm{~h}$ for indicated proteins.

(L-S) Quantification of the relative expression of GRASP55 (L), GRASP65 (M), TGN46 (N), CatD (O), EEA1 (P), LC3-II/LC3-I ratio (Q), GPP130 (R) and ERGIC53 (S), with the level in uninfected cells normalized to 1 .

Data are shown as mean \pm SEM from at least three independent experiments. Statistical analyses are performed using two-tailed Student's t-test. *, $\mathrm{p}<0.05 ;{ }^{* *}, \mathrm{p}<0.01$; ***, $\mathrm{p}<0.001$; n.s., no significance. 


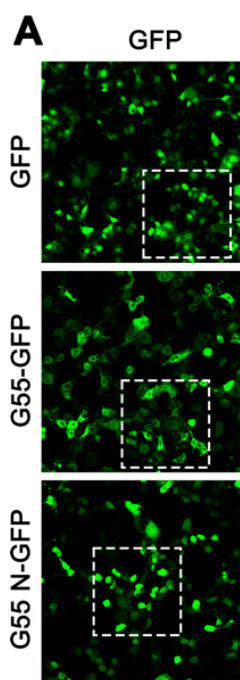

B

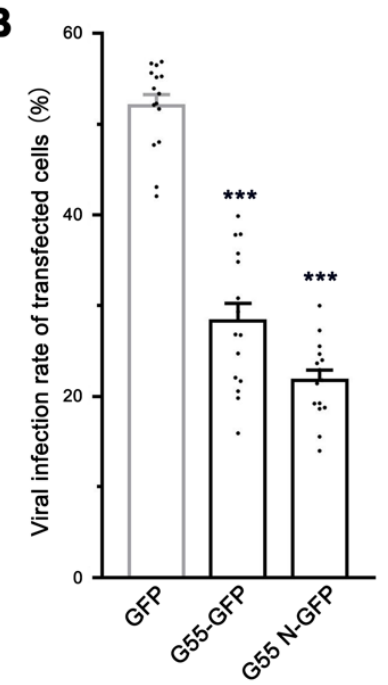

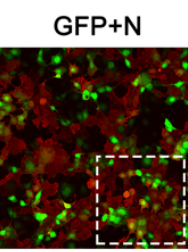
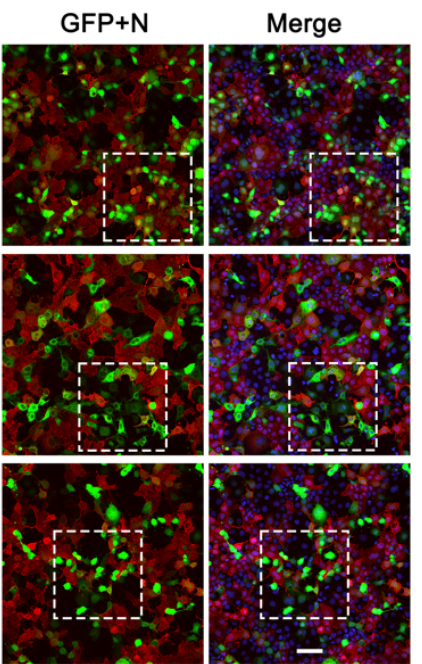

\section{C}
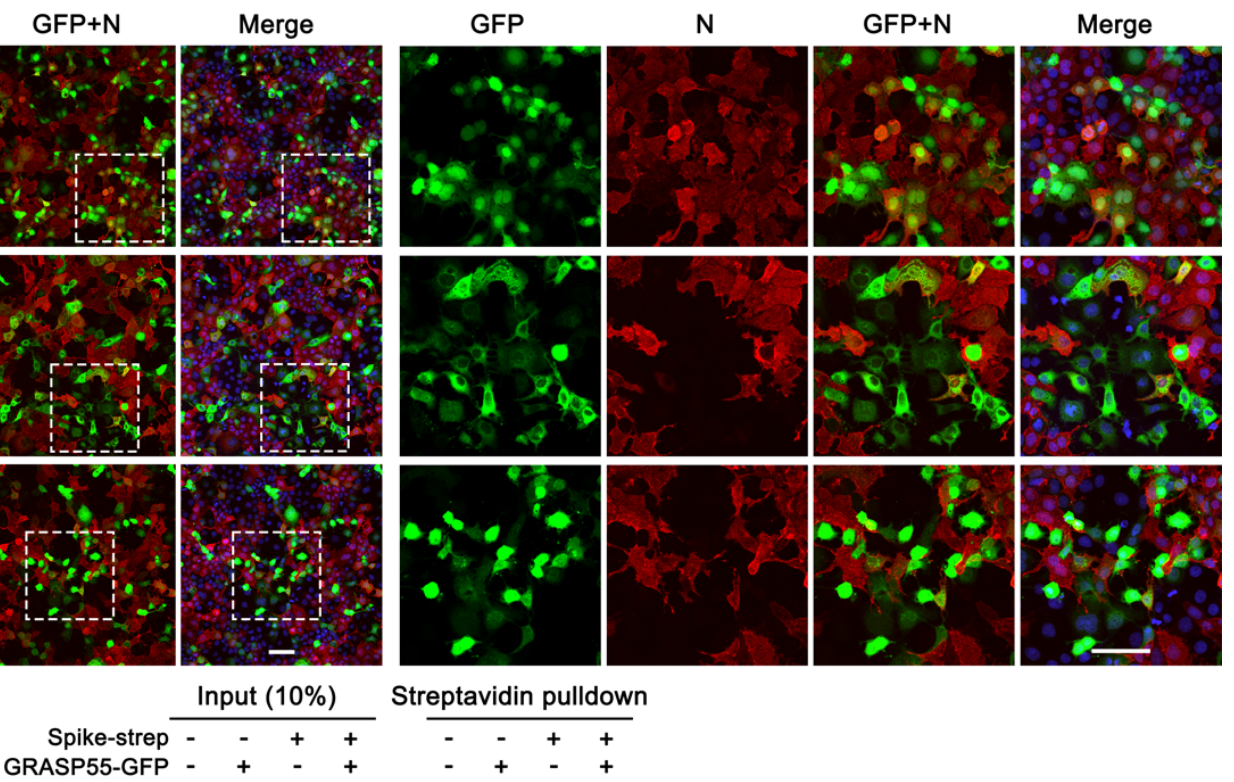

Streptavidin pulldown GRASP55-GFP -
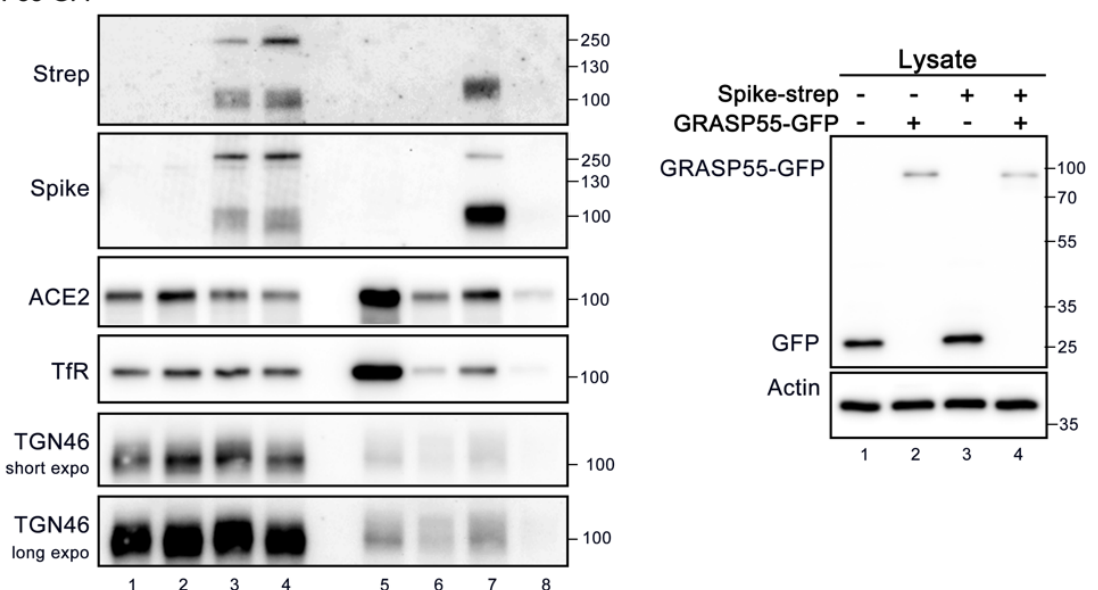

D

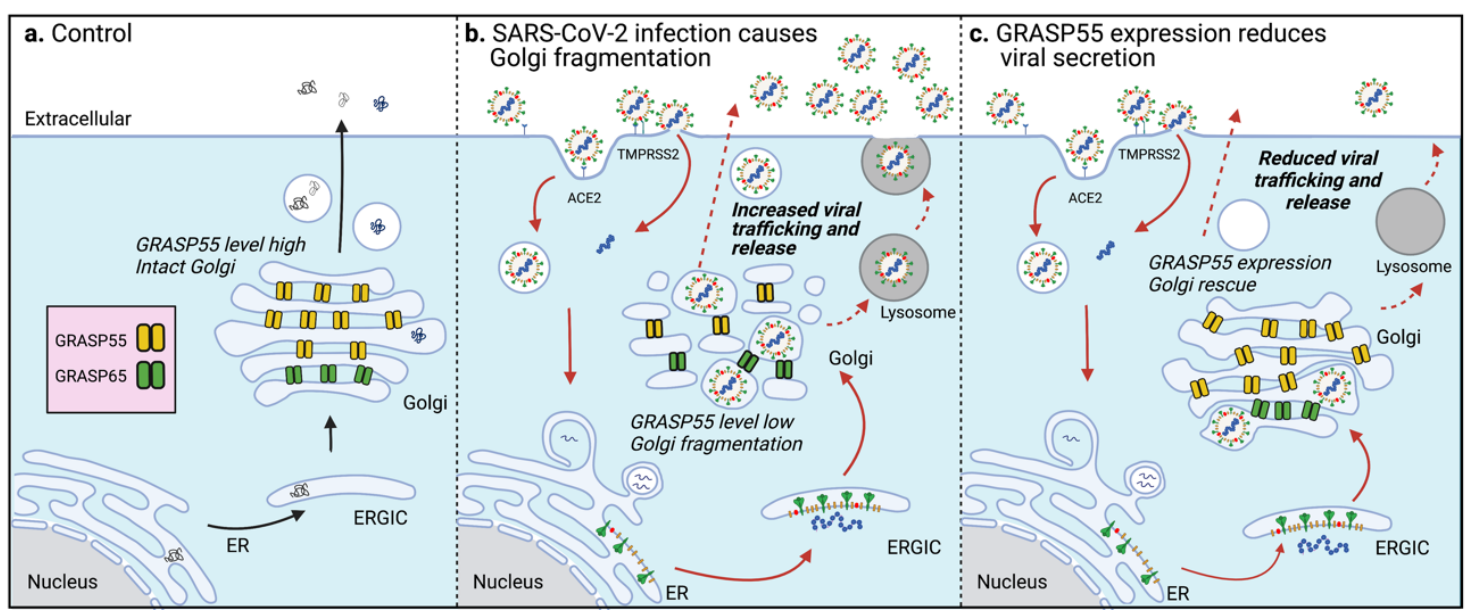

Figure 6. Expression of GRASP55 inhibits viral infection.

(A) GRASP55 expression reduces SARS-CoV-2 infection. Huh7-ACE2 cells were transfected with indicated constructs for $24 \mathrm{~h}$ followed by infection with SARS-CoV-2 for $24 \mathrm{~h}$ and stained for nucleocapsid. Shown are representative fluorescence images. Boxed areas in the left panels are enlarged and shown on the right. Scale bars, $100 \mu \mathrm{m}$. 
(B) Quantification of the viral infection rate of transfected cells in A. Data are shown as mean \pm SEM from 15 random images of one representative replicate from three independent experiments. Statistical analyses are performed using one-way ANOVA, Tukey’s multiple comparison test. ***, $\mathrm{p}<0.001$.

(C) GRASP55 expression reduced spike at the cell surface. Huh7-ACE2 cells were transfected with GFP or GRASP55-GFP for $24 \mathrm{~h}$, and then co-transfection with GFP or GRASP55-GFP together with spike-strep for $24 \mathrm{~h}$. Cell surface proteins were biotinylated, pulled down by streptavidin beads, and blotted for indicated proteins.

(D) Proposed working model for a role of GRASP55 in SARS-CoV-2 infection. In brief, under normal conditions (a) GRASP55 is expressed at a high level and maintains the Golgi in an intact structure. After SARS-CoV-2 infection (b), GRASP55 level is reduced, resulting in Golgi fragmentation that may facilitate viral trafficking. Conversely, when GRASP55 is exogenously expressed (c), the Golgi structure is reinforced and the viral trafficking speed is limited, thus inhibiting viral trafficking and release. 

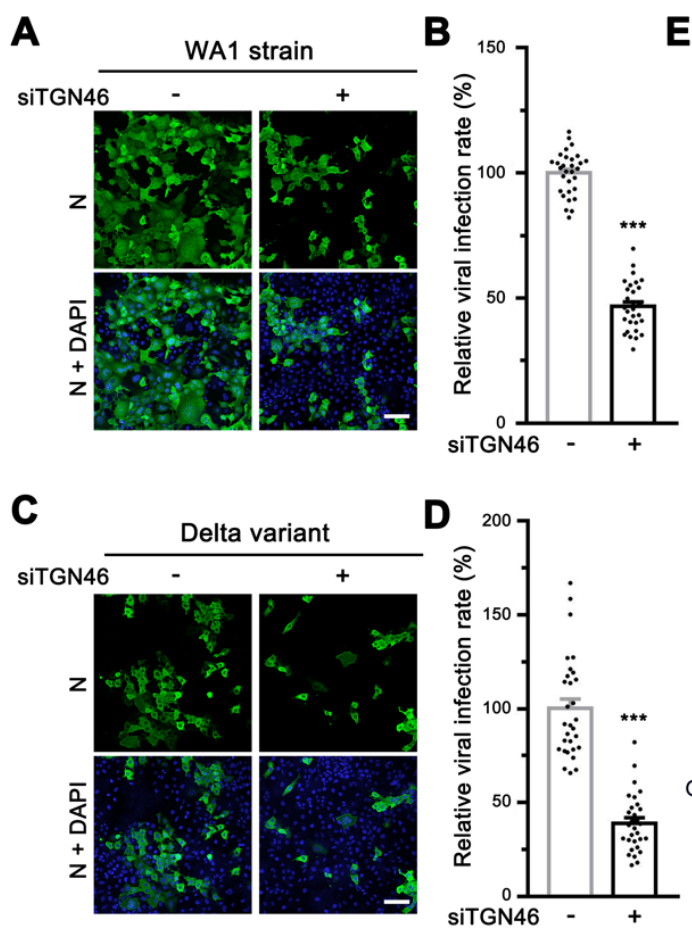

E

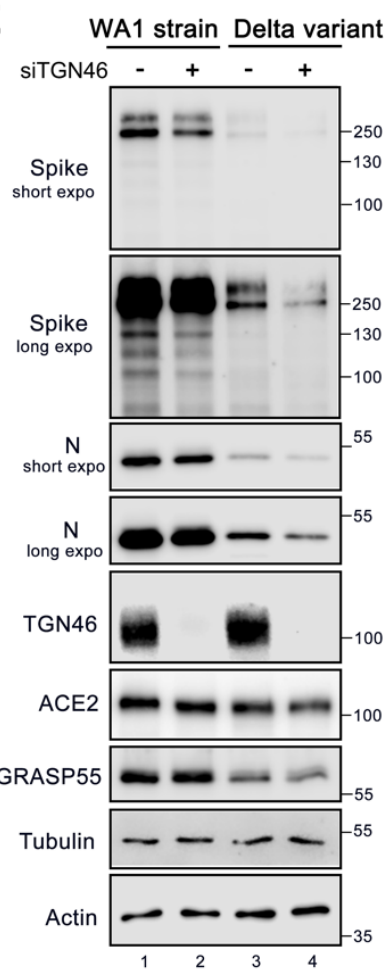

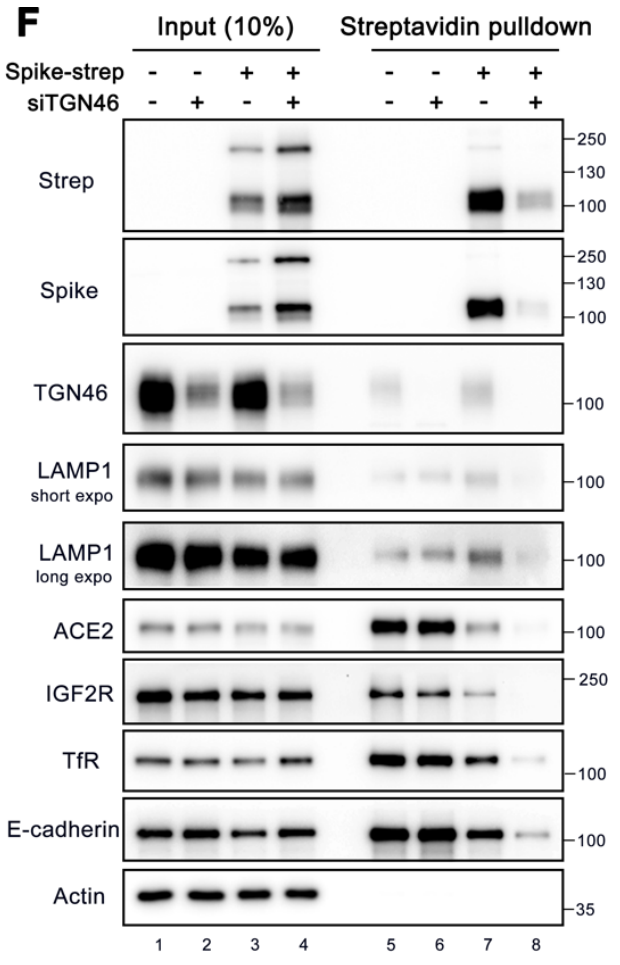

G

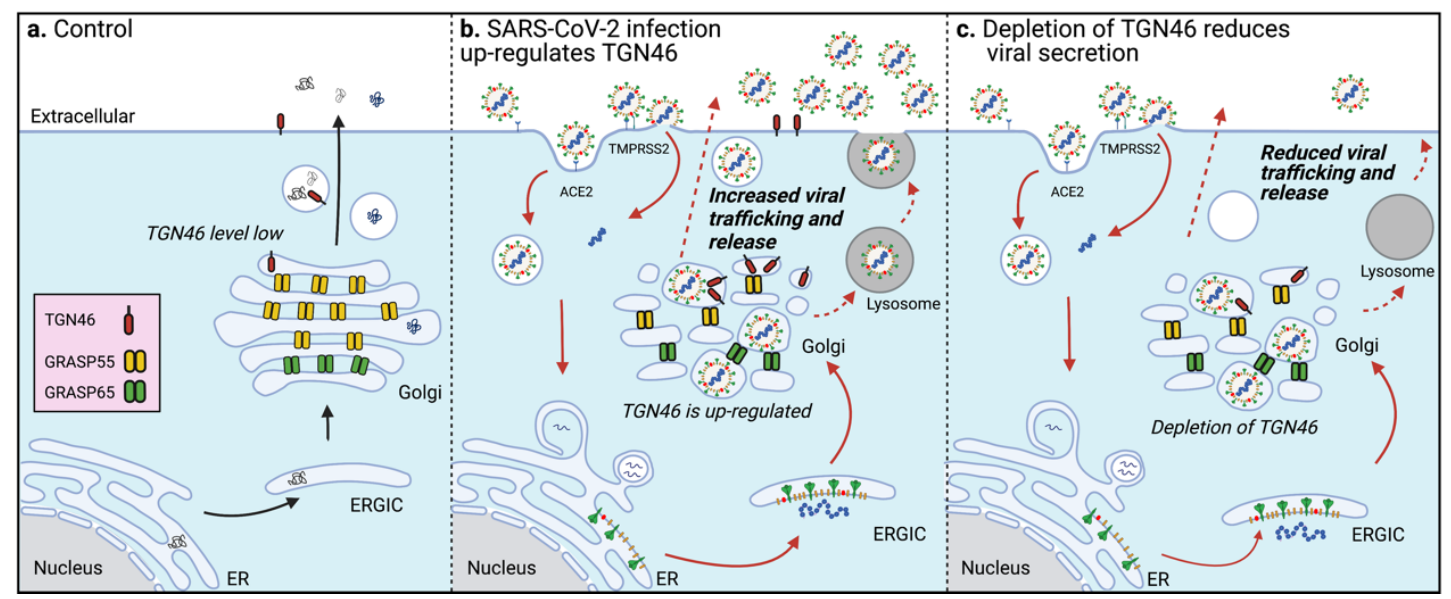

Figure 7. TGN46 facilitates SARS-CoV-2 trafficking.

(A, C) TGN46 depletion reduces SARS-CoV-2 infection. Huh7-ACE2 cells were transfected with siControl or siTGN46 oligos for $48 \mathrm{~h}$ followed by infection with the WA1 strain (A) or Delta variant (C) of SARS-CoV-2 for $24 \mathrm{~h}$ and stained for nucleocapsid. Shown are representative fluorescence images. Scale bars, $100 \mu \mathrm{m}$.

(B, D) Quantification of the viral infection rate in A and C, respectively. Data are shown as mean \pm SEM from 30 random images from two independent experiments. Statistical analyses were performed using two-tailed Student's t-test. ${ }^{* * *}, \mathrm{p}<0.001$.

(E) TGN46 depletion reduces viral protein expression in host cells. Huh7-ACE2 cells were transfected with siControl or siTGN46 oligos for $48 \mathrm{~h}$ followed by infection with SARS-CoV-2 WA1 strain and Delta variant for $24 \mathrm{~h}$. Cell lysates were blotted for indicated proteins. Long and 
short exposures are shown for spike and N proteins.

(F) TGN46 depletion reduces spike protein at the cell surface. Huh7-ACE2 cells were transfected with siControl or siTGN46 oligos for $48 \mathrm{~h}$ followed by transfection with spike-strep for $24 \mathrm{~h}$. Cell surface proteins were biotinylated, pulled down by streptavidin beads, and blotted for indicated proteins. Two different exposures are shown for LAMP1.

(G) Proposed working model for a novel role of TGN46 in SARS-CoV-2 infection. In brief, under normal conditions (a) TGN46 is expressed at a relatively low level and recycling between the Golgi and plasma membrane. After SARS-CoV-2 infection (b), TGN46 is up-regulated, which accelerates viral trafficking. WhenTGN46 is depleted (c), the trafficking speed of all variants of SARS-CoV-2 is reduced. Thus, TGN46 may serve as a carrier for viral trafficking and release. 
bioRxiv preprint doi: https://doi.org/10.1101/2022.03.04.483074; this version posted March 7,2022 . The copyright holder for this preprint (which was not certified by peer review) is the author/funder, who has granted bioRxiv a license to display the preprint in perpetuity. It is made available under aCC-BY-NC-ND 4.0 International license.

\section{Table 1. Summary of morphological changes of subcellular organelles after SARS-CoV-2}

\section{infection}

\begin{tabular}{|c|c|c|c|c|c|c|c|c|c|c|c|}
\hline Subcellular & Marker & Morph. & \multicolumn{3}{|c|}{ Item \# per cell } & \multicolumn{3}{|c|}{ Area per cell } & \multicolumn{3}{|c|}{ Relative Expression level } \\
\hline & & & uninfected & infected & $\begin{array}{c}\mathrm{p}- \\
\text { value }\end{array}$ & uninfected & infected & $\begin{array}{c}\text { p- } \\
\text { value }\end{array}$ & uninfected & infected & $\begin{array}{c}\mathrm{p}- \\
\text { value }\end{array}$ \\
\hline ER & Calreticulin & - & & NA & & $671.8 \pm 30.2$ & $613.0 \pm 34.6$ & n.s. & $1.00 \pm 0.06$ & $0.93 \pm 0.06$ & n.s. \\
\hline ERGIC & ERGIC53 & Dispersed & $131.6 \pm 3.6$ & $95.1 \pm 4.1$ & $* * *$ & $99.9 \pm 4.2$ & $97.4 \pm 4.7$ & n.s. & $1.00 \pm 0.03$ & $0.85 \pm 0.05$ & $*$ \\
\hline \multirow{3}{*}{ Cis-Golgi } & GPP130 & Dispersed & $13.6 \pm 1.0$ & $56.2 \pm 4.3$ & $* * *$ & $52.2 \pm 3.8$ & $63.4 \pm 6.1$ & n.s. & $1.00 \pm 0.06$ & $1.07 \pm 0.10$ & n.s. \\
\hline & GM130 & Dispersed & $15.9 \pm 1.0$ & $70.8 \pm 4.3$ & $* * *$ & $68.6 \pm 2.2$ & $73.3 \pm 7.2$ & & $1.00 \pm 0.03$ & $0.78 \pm 0.08$ & \\
\hline & GRASP65 & Dispersed & $11.7 \pm 0.7$ & $79.2 \pm 5.7$ & $* * *$ & $54.3 \pm 1.7$ & $55.6 \pm 3.0$ & n.s. & $1.00 \pm 0.04$ & $0.87 \pm 0.05$ & n.s. \\
\hline $\begin{array}{c}\text { Medial/Trans- } \\
\text { Golgi }\end{array}$ & GRASP55 & Dispersed & $16 . .8 \pm 1.3$ & $41.2 \pm 1.9$ & $* * *$ & $69.3 \pm 2.7$ & $34.2 \pm 4.6$ & $* * *$ & $1.00 \pm 0.04$ & $0.32 \pm 0.04$ & $* * *$ \\
\hline \multirow{2}{*}{ Trans-Golgi } & GCC88 & Dispersed & $18.8 \pm 1.5$ & $79.1 \pm 5.8$ & $* * *$ & $49.3 \pm 2.4$ & $43.9 \pm 3.2$ & n.s. & $1.00 \pm 0.03$ & $0.79 \pm 0.06$ & $* * *$ \\
\hline & GalT & Dispersed & $20.1 \pm 1.0$ & $54.4 \pm 3.3$ & $* * *$ & $41.2 \pm 1.5$ & $44.3 \pm 2.9$ & n.s. & $1.00 \pm 0.04$ & $0.94 \pm 0.06$ & n.s. \\
\hline \multirow{3}{*}{$\begin{array}{c}\text { Trans-Golgi } \\
\text { network }\end{array}$} & TGN46 & Dispersed & $25.8 \pm 1.4$ & $89.3 \pm 6.2$ & $* * *$ & $33.7 \pm 1.5$ & $92.9 \pm 6.3$ & $* * *$ & $1.00 \pm 0.04$ & $2.37 \pm 0.17$ & $* * *$ \\
\hline & Golgin-245 & Dispersed & $11.6 \pm 0.8$ & $61.5 \pm 4.2$ & $* * *$ & $53.2 \pm 1.6$ & $49.6 \pm 3.9$ & n.s. & $1.00 \pm 0.03$ & $0.64 \pm 0.05$ & $* * *$ \\
\hline & Arl1 & Dispersed & $12.0 \pm 0.9$ & $51.1 \pm 3.4$ & $* * *$ & $58.8 \pm 3.4$ & $56.4 \pm 3.1$ & n.s. & $1.00 \pm 0.04$ & $0.83 \pm 0.07$ & $* * *$ \\
\hline COP-I & $\beta-C O P$ & $\begin{array}{c}\text { Large } \\
\text { granules }\end{array}$ & $112.6 \pm 3.5$ & $79.8 \pm 3.3$ & $* * *$ & $148.5 \pm 6.2$ & $152.8 \pm 7.1$ & n.s. & $1.00 \pm 0.03$ & $0.86 \pm 0.05$ & $*$ \\
\hline COP-II & Sec31 & $\begin{array}{l}\text { Large } \\
\text { granules }\end{array}$ & $142.2 \pm 4.2$ & $115.7 \pm 2.7$ & $* * *$ & $56.6 \pm 3.6$ & $48.1 \pm 3.5$ & n.s. & $1.00 \pm 0.04$ & $0.72 \pm 0.03$ & $* * *$ \\
\hline $\begin{array}{l}\text { Clathrin-coated } \\
\text { vesicles }\end{array}$ & $\begin{array}{c}\text { Clathrin } \\
\text { heavy chain }\end{array}$ & Dispersed & $66.5 \pm 3.6$ & $65.0 \pm 4.2$ & n.s. & $40.7 \pm 4.5$ & $34.9 \pm 3.7$ & n.s. & $1.00 \pm 0.06$ & $0.90 \pm 0.08$ & n.s. \\
\hline \multirow{2}{*}{ Endosome } & EEA1 & $\begin{array}{c}\text { Large } \\
\text { granules }\end{array}$ & $62.3 \pm 2.4$ & $31.2 \pm 2.1$ & $* * *$ & $19.3 \pm 0.9$ & $19.1 \pm 1.3$ & n.s. & $1.00 \pm 0.04$ & $1.14 \pm 0.11$ & n.s. \\
\hline & Rab7 & $\begin{array}{c}\text { Large } \\
\text { granules }\end{array}$ & $111.2 \pm 5.1$ & $118.8 \pm 6.9$ & n.s. & $22.3 \pm 1.1$ & $50.1 \pm 4.2$ & $* * *$ & $1.00 \pm 0.05$ & $2.24 \pm 0.18$ & $* * *$ \\
\hline Autophagosome & LC3 & $\begin{array}{c}\text { Large \& } \\
\text { more } \\
\text { granules }\end{array}$ & $93.2 \pm 3.8$ & $104.7 \pm 4.9$ & $* * *$ & $58.5 \pm 8.1$ & $63.0 \pm 5.4$ & n.s. & $1.00 \pm 0.06$ & $1.20 \pm 0.10$ & n.s. \\
\hline \multirow{2}{*}{ Lysosome } & CatD & $\begin{array}{c}\text { Larger } \\
\text { granules }\end{array}$ & $126.7 \pm 7.0$ & $106.4 \pm 6.2$ & $*$ & $79.8 \pm 6.5$ & $69.0 \pm 6.4$ & n.s. & $1.00 \pm 0.07$ & $0.90 \pm 0.07$ & n.s. \\
\hline & LAMP2 & $\begin{array}{c}\text { Large } \\
\text { granules }\end{array}$ & $128.1 \pm 5.1$ & $99.5 \pm 5.5$ & $* * *$ & $143.1 \pm 7.3$ & $146.3 \pm 14.1$ & n.s. & $1.00 \pm 0.05$ & $0.97 \pm 0.09$ & n.s. \\
\hline \multirow{2}{*}{ Cytoskeleton } & Tubulin & - & \multicolumn{3}{|c|}{ NA } & $956.6 \pm 28.5$ & $784.5 \pm 30.3$ & $* * *$ & $1.00 \pm 0.03$ & $0.91 \pm 0.06$ & n.s. \\
\hline & Actin & - & \multicolumn{3}{|c|}{ NA } & $472.9 \pm 20.4$ & $501.4 \pm 19.7$ & n.s. & $1.00 \pm 0.05$ & $1.08 \pm 0.05$ & n.s. \\
\hline
\end{tabular}

All quantitation data are shown as mean \pm SEM from three independent experiments. Statistical analyses were performed using two-tailed Student's t-test. ${ }^{*}, \mathrm{p}<0.05$; ***, $\mathrm{p}<0.001$; n.s., no significance. 


\section{Supplemental figures and figure legend}
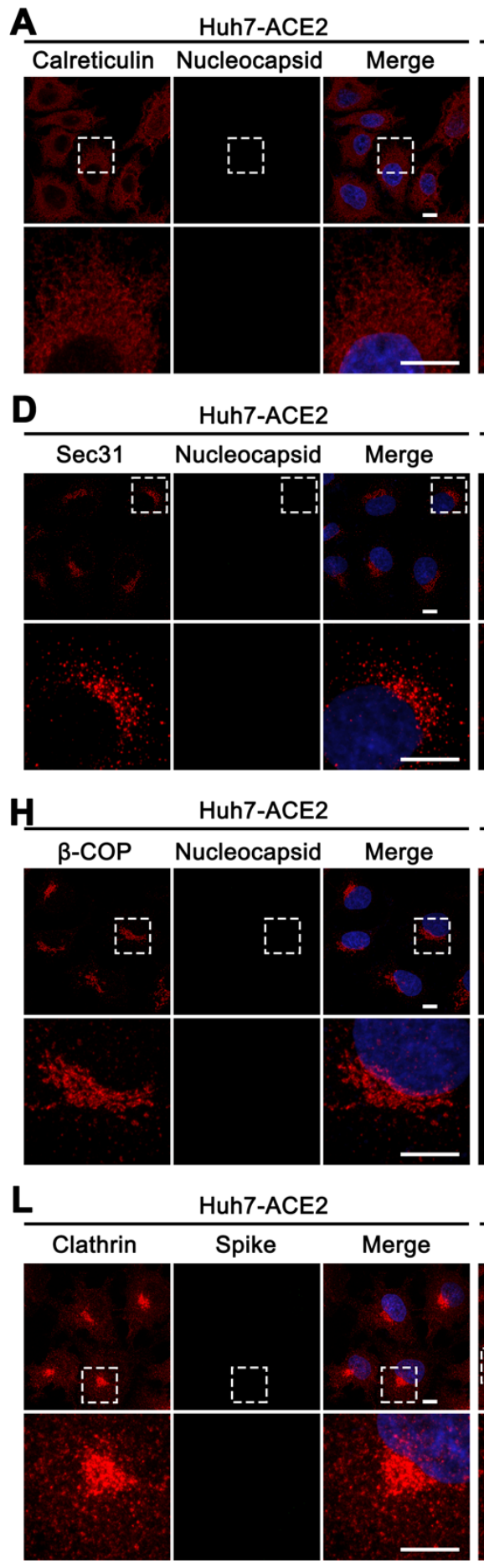

Huh7-ACE2 + SARS-CoV-2

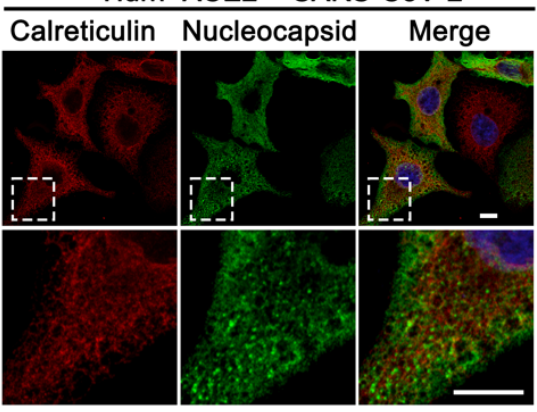

Huh7-ACE2 + SARS-CoV-2
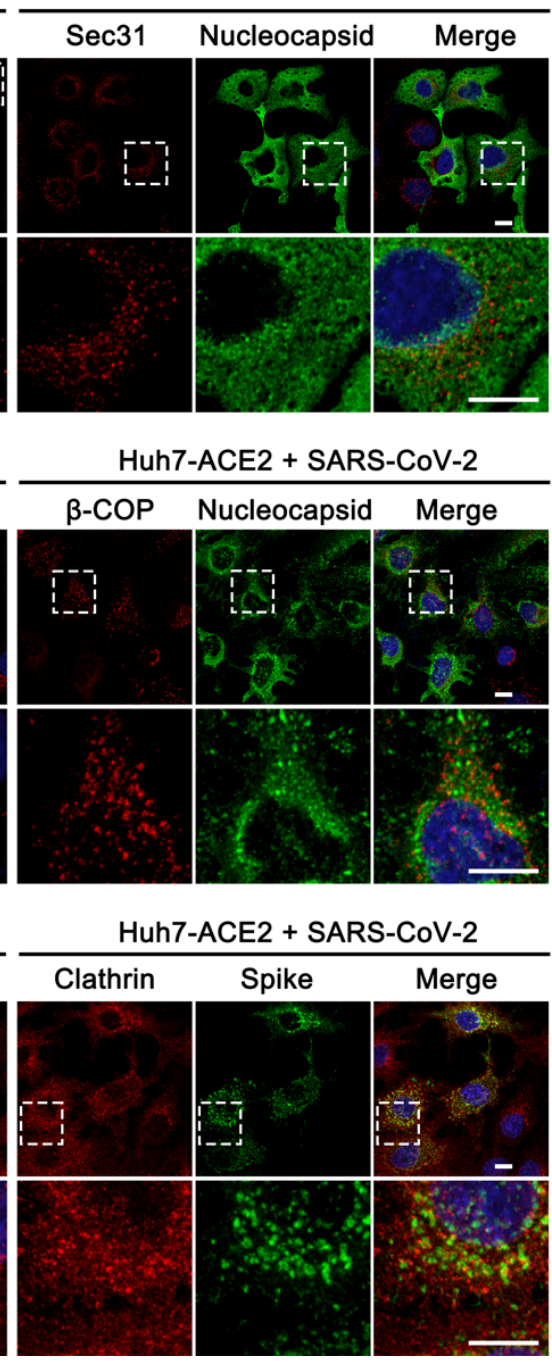

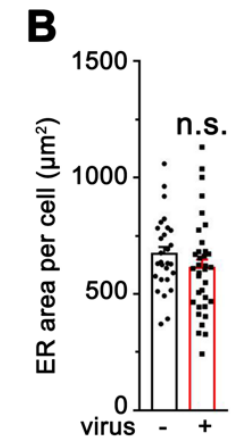

C
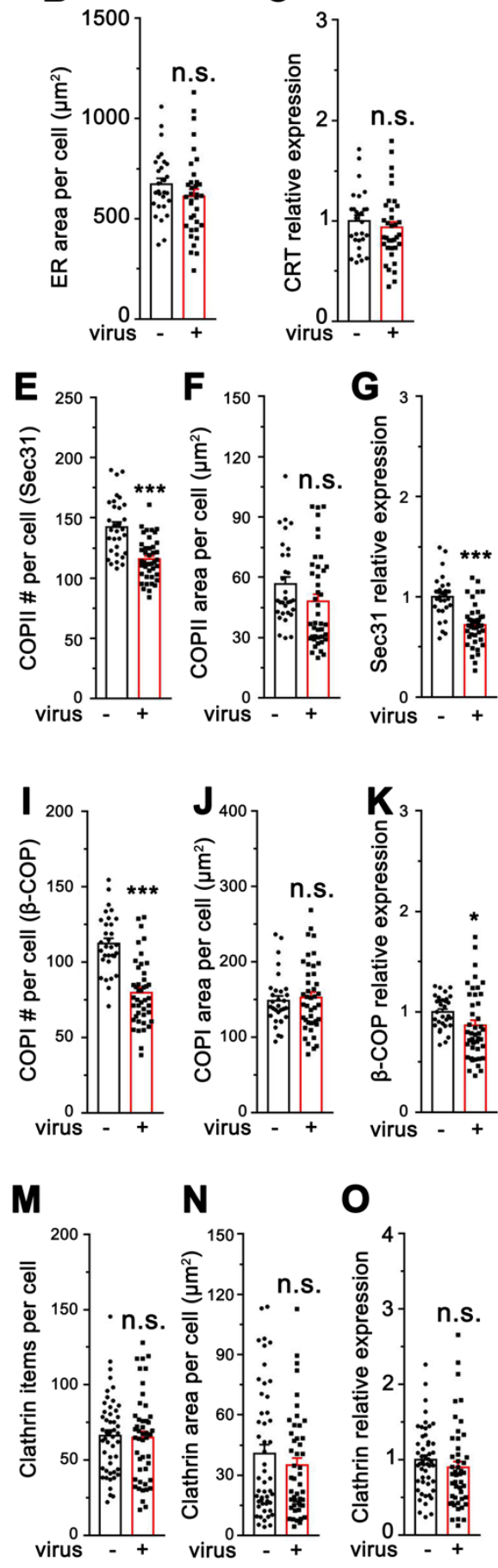

Figure S1. SARS-CoV-2 infection modulates the formation of COPI and COPII vesicles.

(A) Representative confocal images of Huh7-ACE2 cells incubated with or without SARS-CoV-2 $(\mathrm{MOI}=1)$ for $24 \mathrm{~h}$ and stained for calreticulin and nucleocapsid.

(B-C) Quantification of calreticulin for the number of area (B) and relative expression (C) in A.

(D) Representative confocal images of Huh7-ACE2 cells incubated with or without SARS-CoV-2 
$(\mathrm{MOI}=1)$ for $24 \mathrm{~h}$ and stained for Sec31 and nucleocapsid.

(E-G) Quantification of Sec31 item number $(E)$, area $(F)$, and relative expression $(G)$ in $D$.

(H) Representative confocal images of Huh7-ACE2 cells incubated with or without SARS-CoV-2 $(\mathrm{MOI}=1)$ for $24 \mathrm{~h}$ and stained for $\beta-\mathrm{COP}$ and spike.

(I-K) Quantification of $\beta$-COP in H.

(L) Representative confocal images of Huh7-ACE2 cells incubated with or without SARS-CoV-2 $(\mathrm{MOI}=1)$ for $24 \mathrm{~h}$ and stained for clathrin and nucleocapsid.

(M-O) Quantification of clathrin in L.

Boxed areas in the upper panels are enlarged and shown underneath. Scale bars in all panels, $10 \mu \mathrm{m}$. All quantitation data are shown as mean \pm SEM from three independent experiments. Statistical analyses were performed using two-tailed Student's t-test. *, p $<0.05$; ***, p $<0.001$; n.s., no significance. 


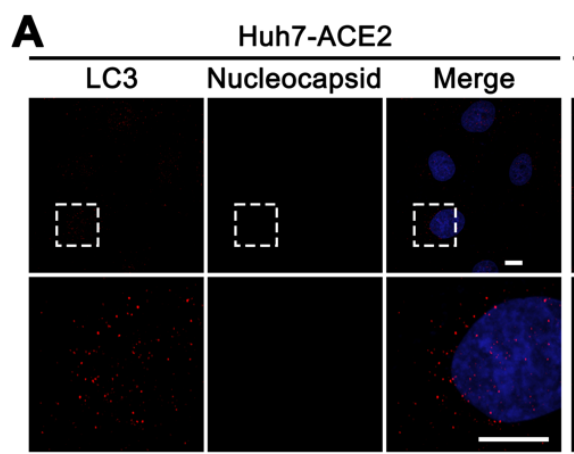

E
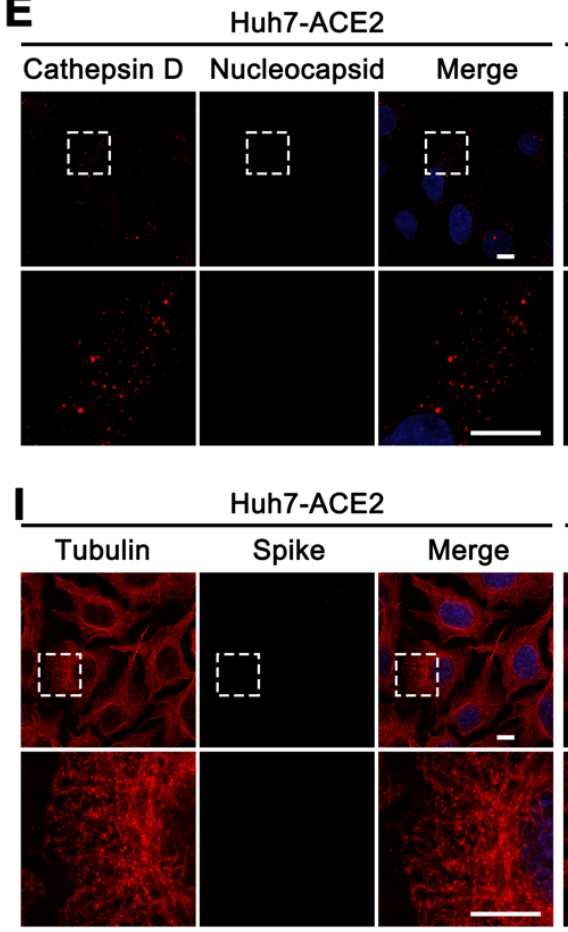

$\mathbf{L}$

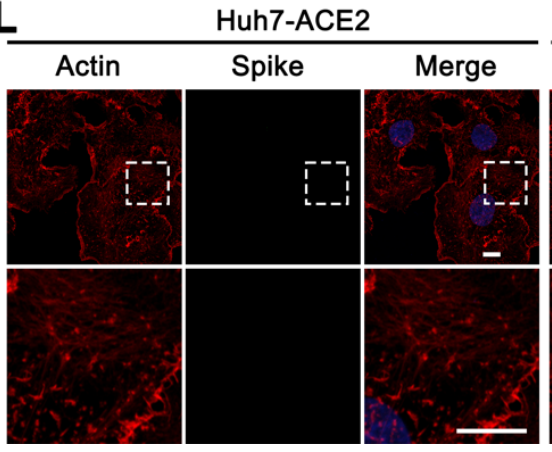

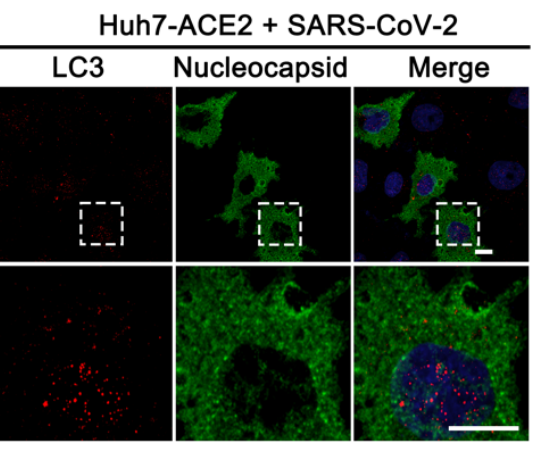

Huh7-ACE2 + SARS-CoV-2 F

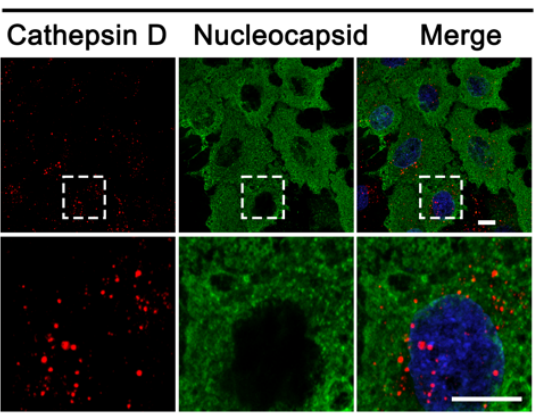

Huh7-ACE2 + SARS-CoV-2

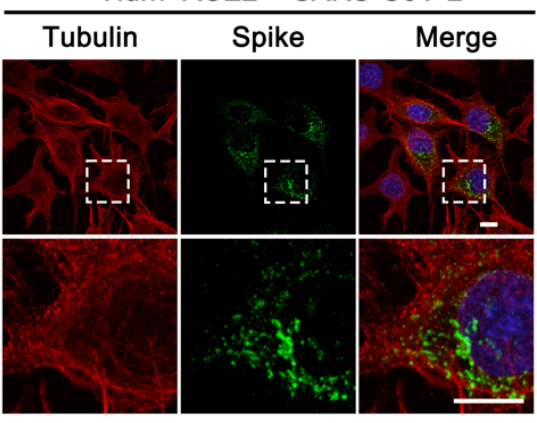

Huh7-ACE2 + SARS-CoV-2

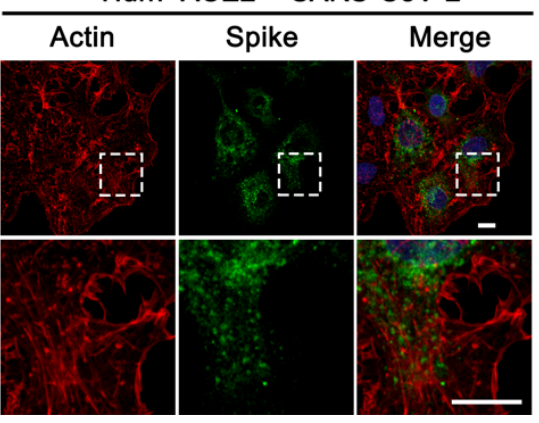

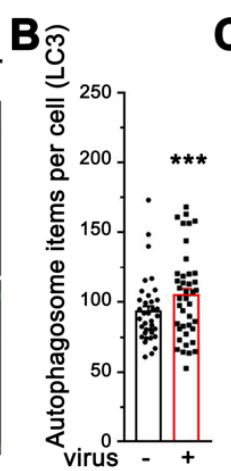

C

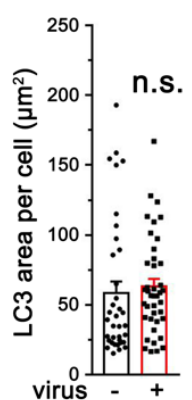

$\mathbf{G}$
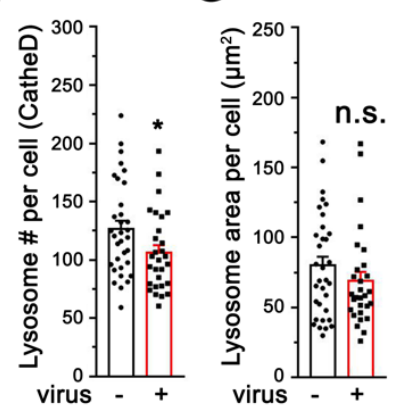

H
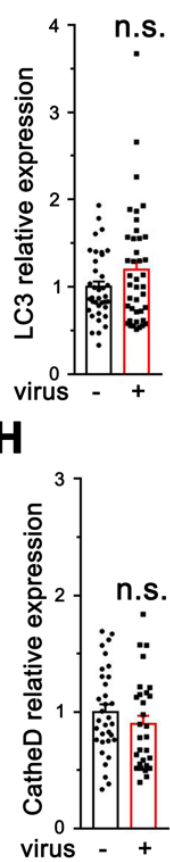

$\mathbf{K}$
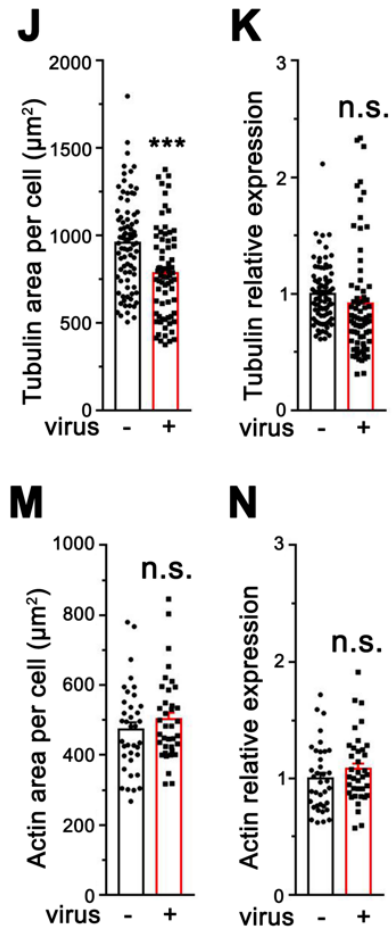

$\mathbf{N}$

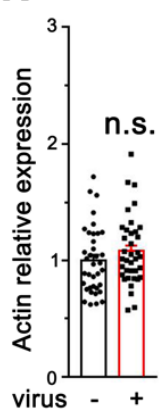

Figure S2. SARS-CoV-2 infection increases autophagy but exhibits minor effects on cytoskeleton.

(A) Representative confocal images of Huh7-ACE2 cells incubated with or without SARS-CoV-2 $(\mathrm{MOI}=1)$ for $24 \mathrm{~h}$ and stained for LC3 and nucleocapsid.

(B-D) Quantification of LC3 item number (B), area (C), and relative expression (D) in A.

(E) Representative confocal images of Huh7-ACE2 cells incubated with or without SARS-CoV-2 $(\mathrm{MOI}=1)$ for $24 \mathrm{~h}$ and stained for cathepsin D and nucleocapsid.

(F-H) Quantification of cathepsin D in E. 
(I) Representative confocal images of Huh7-ACE2 cells incubated with or without SARS-CoV-2 (MOI =1) for $24 \mathrm{~h}$ and stained for $\alpha$-Tubulin and spike.

(J-K) Quantification of tubulin in I.

(L) Representative confocal images of Huh7-ACE2 cells incubated with or without SARS-CoV-2 $(\mathrm{MOI}=1)$ for $24 \mathrm{~h}$ and stained for actin (with phalloidin) and spike.

(M-N) Quantification of actin in L.

Boxed areas in the upper panels are enlarged and shown underneath. Scale bars in all panels, $10 \mu \mathrm{m}$.

All quantitation data are shown as mean \pm SEM from three independent experiments. Statistical analyses were performed using two-tailed Student's t-test. *, p $<0.05$; ***, p $<0.001$; n.s., no significance.
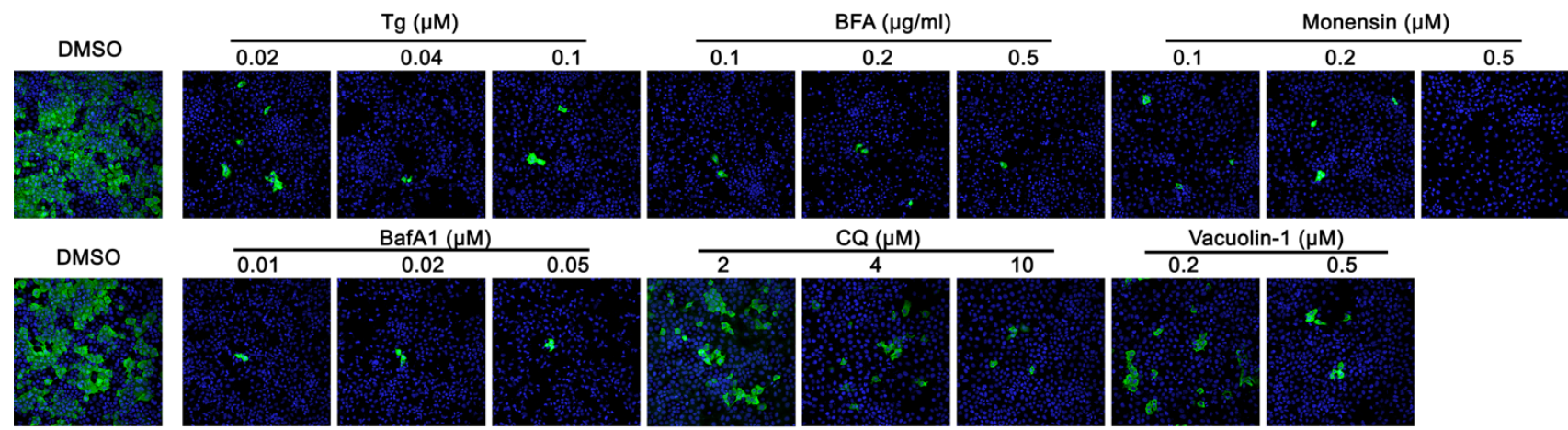

$\mathrm{CQ}(\mu \mathrm{M})$
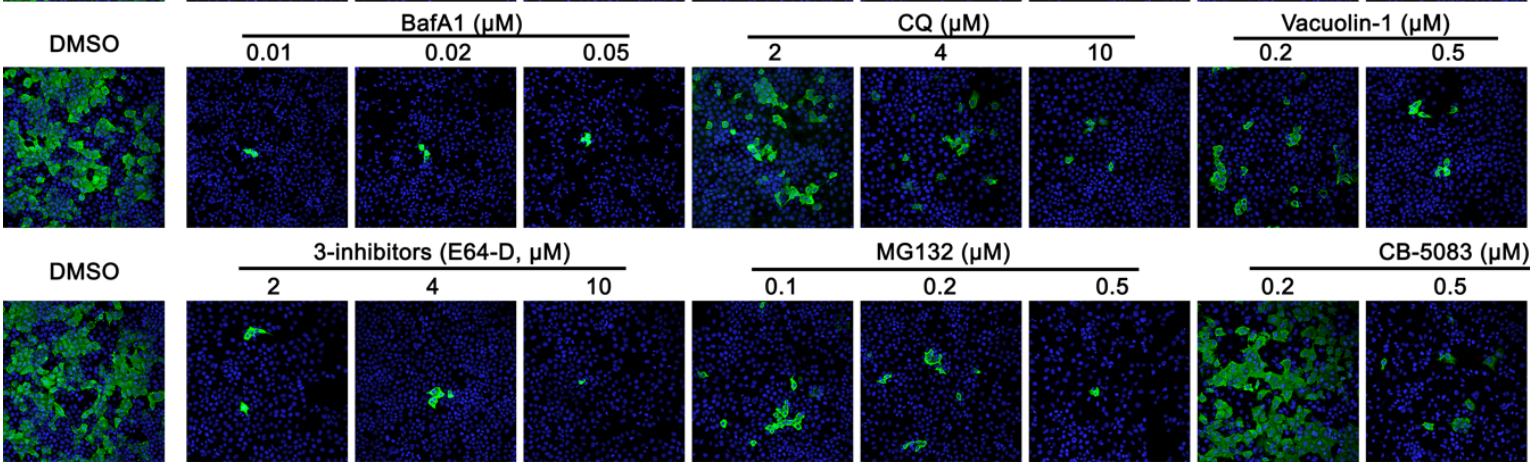

-inhibitors (E64-D, $\mu \mathrm{M})$
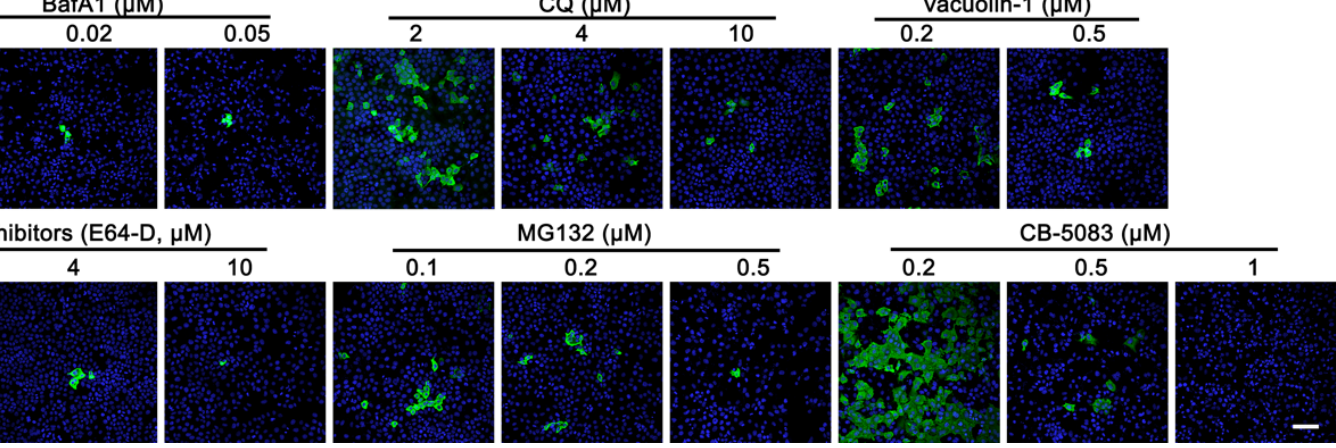

Figure S3. Molecules disrupting Golgi functions inhibit SARS-CoV-2 infection at low

\section{concentrations.}

Representative immunofluorescence images of Huh7-ACE2 cells infected with SARS-CoV-2 for 24

$\mathrm{h}$ in the presence of indicated molecules and stained for nucleocapsid. Scale bar, $100 \mu \mathrm{m}$.

Quantification of the viral infection rate is shown in Figure 2C. 
bioRxiv preprint doi: https://doi.org/10.1101/2022.03.04.483074; this version posted March 7, 2022. The copyright holder for this preprint (which was not certified by peer review) is the author/funder, who has granted bioRxiv a license to display the preprint in perpetuity. It is made available under aCC-BY-NC-ND 4.0 International license.
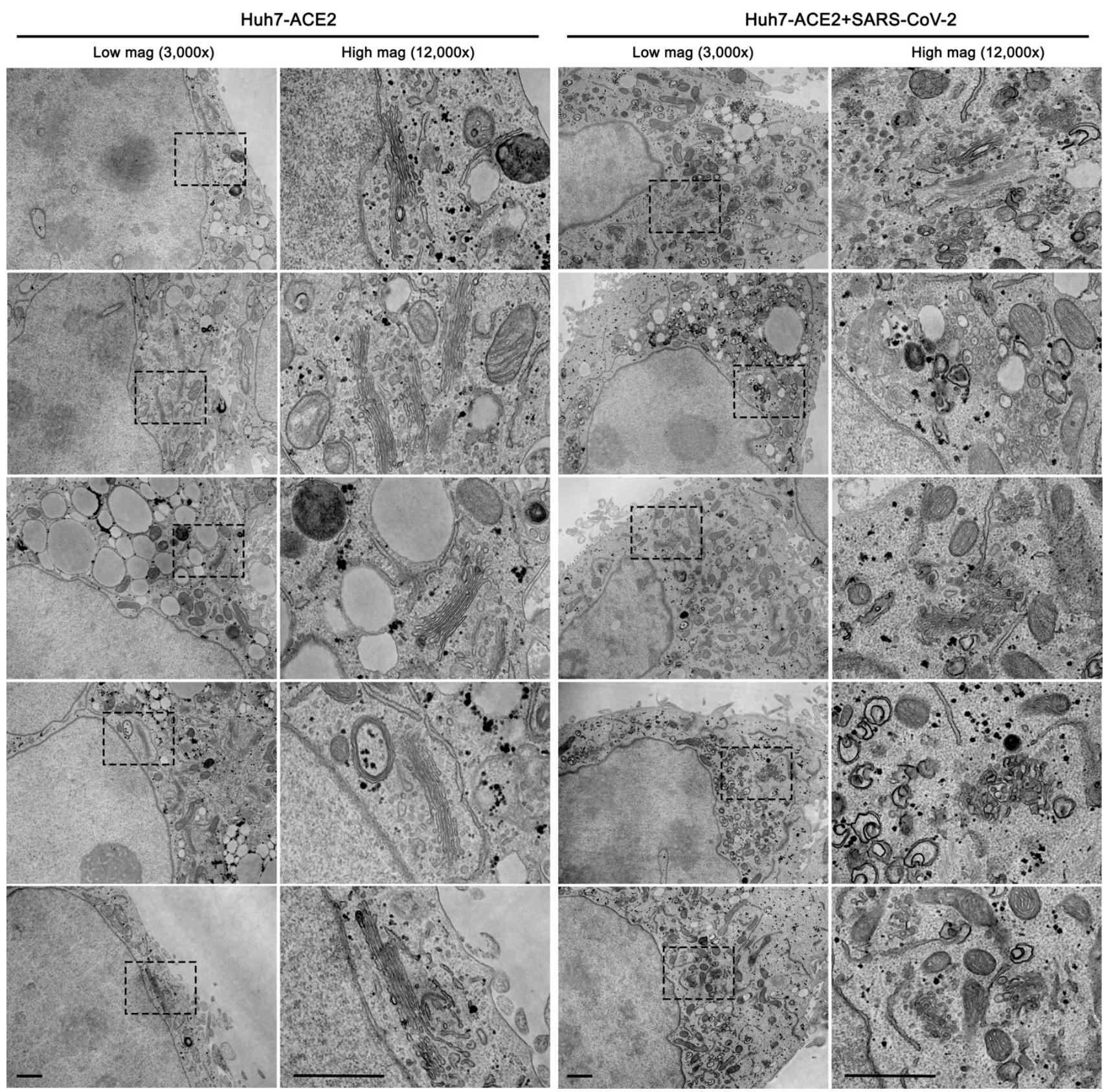

Figure S4. SARS-CoV-2 remodels the Golgi and viral particles accumulate in Golgi fragments.

A gallery of EM images of Huh7-ACE2 cells incubated with or without SARS-CoV-2 $(\mathrm{MOI}=1)$ for $24 \mathrm{~h}$ under two different magnifications. Boxed areas on the left images are enlarged and shown on the right. Scale bars, $500 \mathrm{~nm}$. 


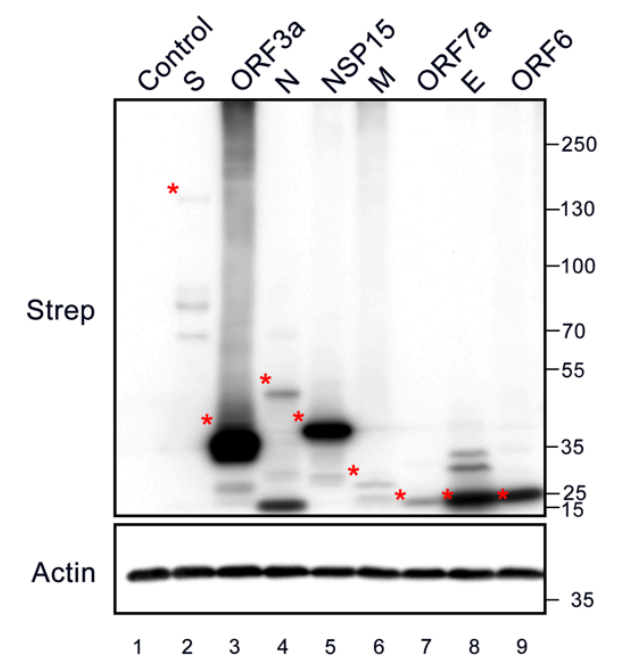

Figure S5. Expression of SARS-CoV-2 proteins in Vero E6 cells.

Immunoblots of indicated Golgi protein in Vero E6 cells transfected with indicated Strep-tagged

SARS-CoV-2 proteins for $24 \mathrm{~h}$. Asterisks indicate the correct bands of the full-length viral proteins. 

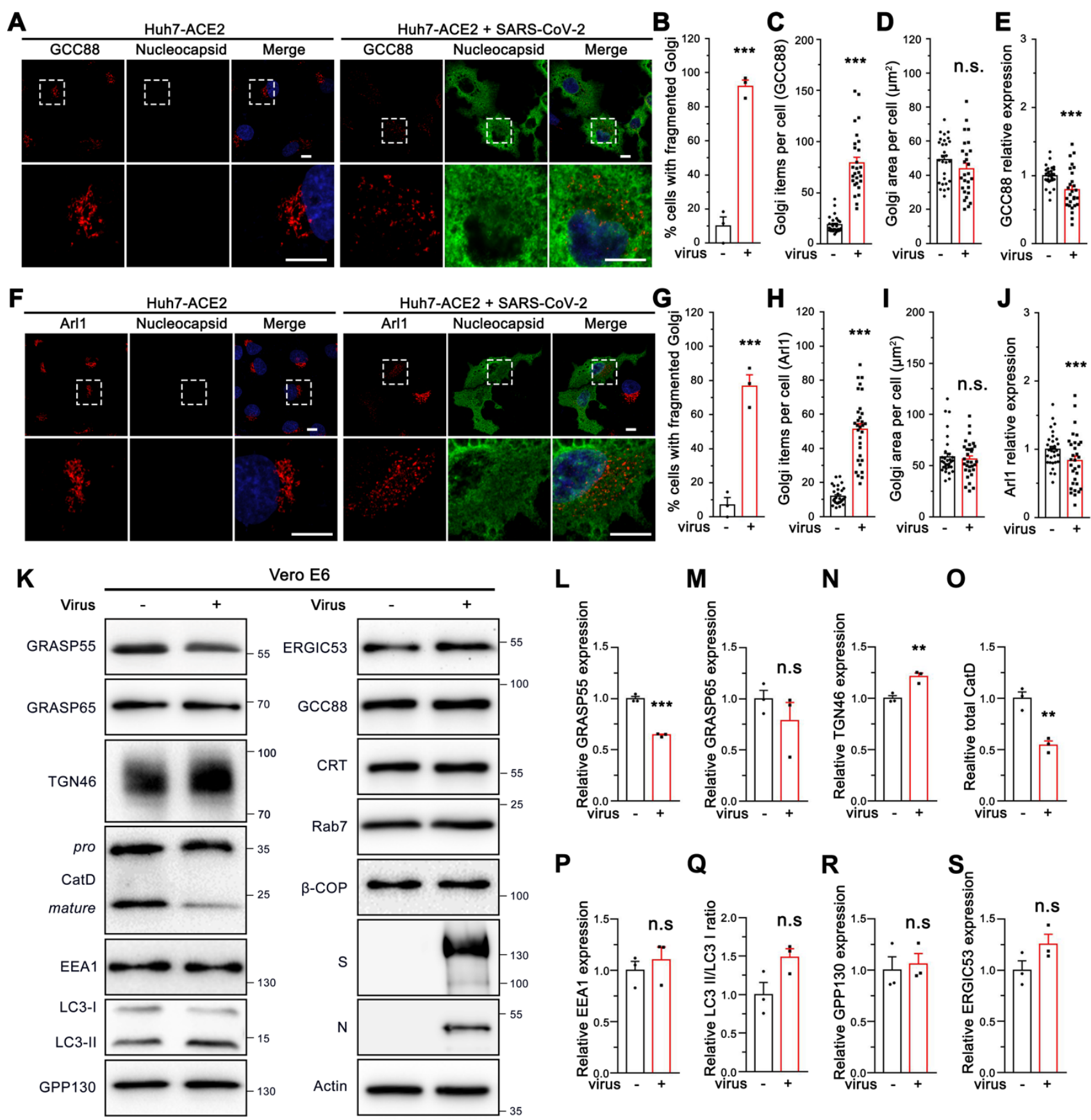

0
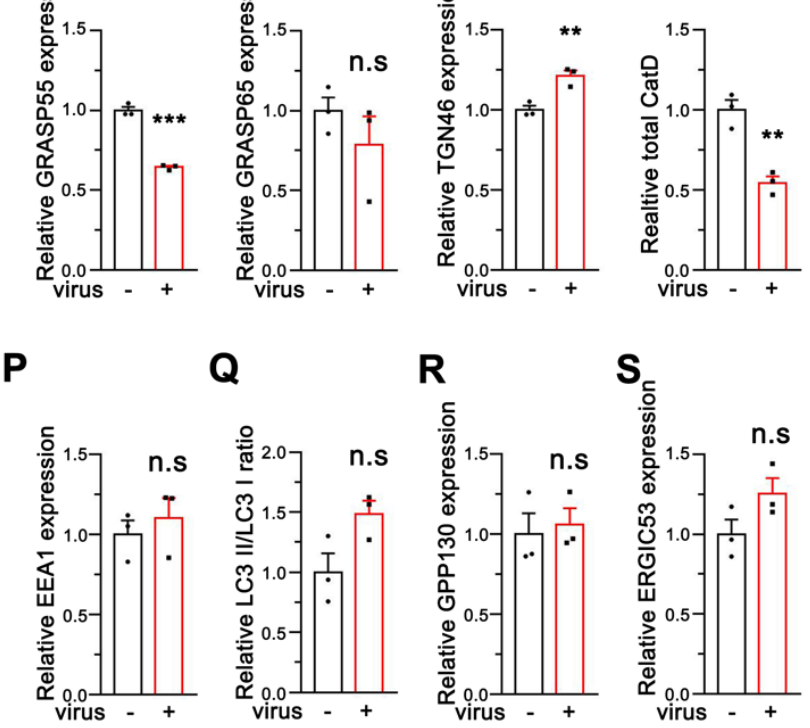

Figure S6. SARS-CoV-2 infection alters the Golgi structure and GRASP55 and TGN46 expression.

(A) Representative confocal images of Huh7-ACE2 cells incubated with or without SARS-CoV-2

$(\mathrm{MOI}=1)$ for $24 \mathrm{~h}$ and stained for a trans-Golgi marker GCC88 and nucleocapsid.

(B-E) Quantification of A for the percentage of cells with fragmented Golgi (B), GCC88 item number $(C)$, area (D), and relative expression level (E).

(F) Representative confocal images of Huh7-ACE2 cells incubated with or without SARS-CoV-2 $(\mathrm{MOI}=1)$ for $24 \mathrm{~h}$ and stained for a trans-Golgi marker Arl1 and nucleocapsid. Boxed areas in the upper panels of A and F are enlarged and shown underneath. Scale bars, $10 \mu \mathrm{m}$. 
(G-J) Quantification of Arl1 in F.

(K) Immunoblots of indicated proteins in Vero E6 cells incubated with or without SARS-CoV-2 $(\mathrm{MOI}=1)$ for $24 \mathrm{~h}$.

(L-S) Quantification of K for the relative level of GRASP55 (L), GRASP65 (M), TGN46 (N), cathepsin D (CatD, O), EEA1 (P), LC3-II/LC3-I ratio (Q), GPP130 (R) and ERGIC53 (S) in K.

Quantitation data are shown as mean \pm SEM from at least three independent experiments. Statistical analyses were performed using two-tailed Student's t-test. ${ }^{* *}, \mathrm{p}<0.01 ; * *, \mathrm{p}<0.001 ;$ n.s., no significance.

A

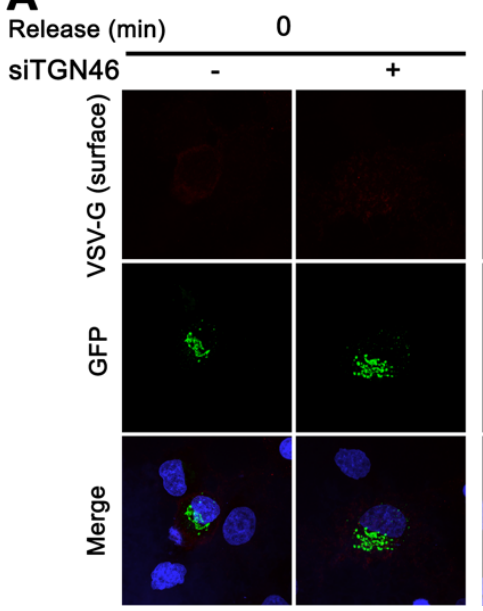

30

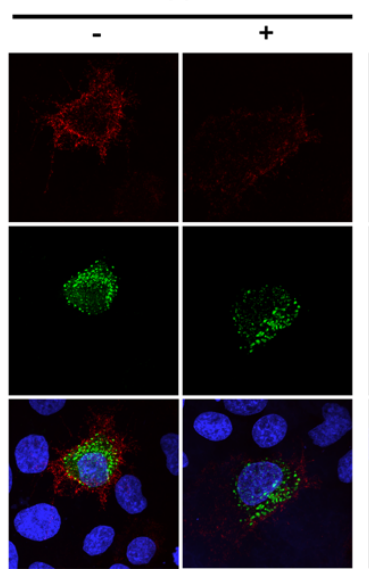

60

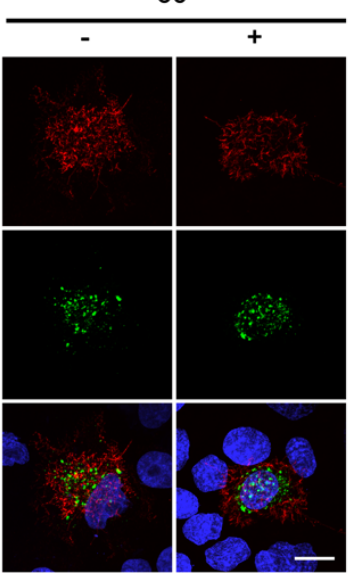

B

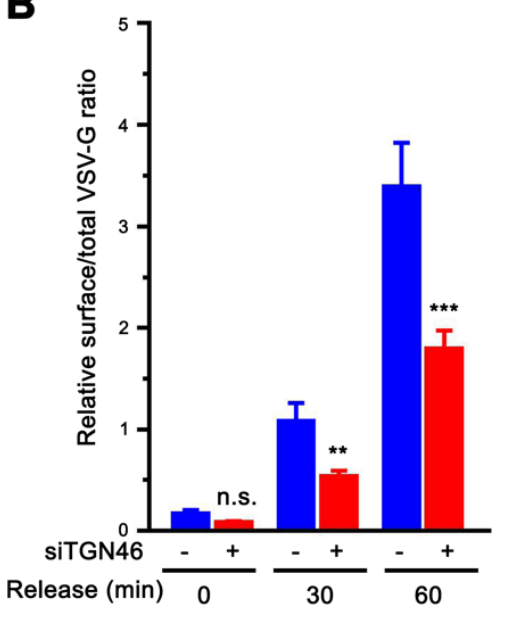

Figure S7. TGN46 facilitates Golgi-to-plasma membrane trafficking

(A) Representative confocal images of Huh7-ACE2 cells in a VSV-G trafficking assay. In brief, cells were transfected with siControl or siTGN46 for $48 \mathrm{~h}$ and then with an Str-Ii_VSV-G-SBP-EGFP plasmid for $24 \mathrm{~h}$. Cells were then treated with $40 \mu \mathrm{M}$ biotin at $20^{\circ} \mathrm{C}$ for $2 \mathrm{~h}$ to accumulate VSV-GGFP (green) in the TGN, shifted to $37^{\circ} \mathrm{C}$ for indicated times to release VSV-G for trafficking to the plasma membrane, and stained for the surface VSV-G protein (red) without permeabilization. Scale bar, $10 \mu \mathrm{m}$.

(B) Quantification of the surface VSV-G/total VSV-G ratio in A. Data are shown as mean $\pm \mathrm{SEM}$ from three independent experiments. Statistical analyses were performed using two-tailed Student's ttest. ${ }^{* *}, \mathrm{p}<0.01 ; * * *, \mathrm{p}<0.001 ;$ n.s., no significance. 


\section{Supplemental movies}

\section{Movie S1. Intact Golgi in a control cell.}

3D reconstruction of Huh7-ACE2 cells stained for GM130. Images were taken for totally 40 stacks and maximum intensity projection was performed.

\section{Movie S2. SARS-CoV-2 infection causes Golgi fragmentation.}

Huh7-ACE2 cells were infected with SARS-CoV-2 (MOI = 1) for $24 \mathrm{~h}$, fixed by 4\% PFA, and stained for spike and GM130. Images were taken for totally 40 stacks and maximum intensity projection was performed. Note the colocalization of spike and GM130 in the Golgi fragments. 


\section{Supplementary Table 1. Antibody list used in this study.}

\begin{tabular}{|c|c|c|}
\hline REAGENT or RESOURCE & SOURCE & IDENTIFIER \\
\hline Mouse monoclonal anti-SARS-CoV-2 N & ProSci & Cat\# ABIN6952432 \\
\hline Rabbit polyclonal anti-SARS-CoV-2 spike & ProSci & Cat\# 3525 \\
\hline Mouse monoclonal anti-Strep Tag & Qiagen & Cat\# 34850; RRID: AB_2810987 \\
\hline Rabbit polyclonal anti-ACE2 & Proteintech Group & Cat\# 21115-1-AP; RRID: AB_10732845 \\
\hline Rabbit polyclonal anti-Calreticulin & Proteintech Group & Cat\# 27298-1-AP; RRID: AB_2880835 \\
\hline Rabbit polyclonal anti-ERGIC53 & Proteintech Group & Cat\# 13364-1-AP; RRID: AB_2135994 \\
\hline Rabbit polyclonal anti-GPP130 & Biolegend & Cat\# 923801; RRID: AB_2565442 \\
\hline Mouse monoclonal anti-GM130 & BD Biosciences & Cat\# 610823; RRID: AB_398142 \\
\hline Rabbit polyclonal anti-GRASP65 & $\begin{array}{l}\text { Gift from Joachim } \\
\text { Seemann }\end{array}$ & N/A \\
\hline Rabbit polyclonal anti-GRASP55 & Proteintech Group & Cat\# 10598-1-AP; RRID: AB_2113473 \\
\hline Rabbit polyclonal anti-GCC88 & Proteintech Group & Cat\# 16271-1-AP, RRID: AB_2107197 \\
\hline Rabbit polyclonal anti-Golgin-97 & Proteintech Group & Cat\# 12640-1-AP; RRID: AB_2115315 \\
\hline Rabbit polyclonal anti-GalT & Novus & Cat\# NBP1-88654; RRID: AB_11018155 \\
\hline Sheep polyclonal anti-TGN46 & Bio-Rab/AbD Serotec & Cat\# AHP500; RRID: AB_324049 \\
\hline Mouse monoclonal anti-Golgin-245 & BD Biosciences & Cat\# 611280; RRID: AB_398809 \\
\hline Rabbit monoclonal anti-Arl1 & Abcam & Cat\# ab155982 \\
\hline Rabbit polyclonal anti- $\beta$-COP & $\begin{array}{l}\text { Gift from Felix } \\
\text { Wieland }\end{array}$ & N/A \\
\hline Rabbit polyclonal anti-Sec31 & $\begin{array}{l}\text { Gift from Fred } \\
\text { Gorelick }\end{array}$ & $\mathrm{N} / \mathrm{A}$ \\
\hline Mouse monoclonal anti-Clathrin heavy chain & $\begin{array}{l}\text { Gift from Frances } \\
\text { Brodsky }\end{array}$ & N/A \\
\hline Mouse monoclonal anti-EEA1 & $\begin{array}{l}\text { Santa Cruz } \\
\text { Biotechnology }\end{array}$ & Cat\#sc-365652; RRID: AB_10850311 \\
\hline Rabbit polyclonal anti-Rab7 & Proteintech Group & Cat\# 55469-1-AP; RRID: AB_11182831 \\
\hline Rabbit polyclonal anti-LC3B & $\begin{array}{l}\text { Cell Signaling } \\
\text { Technology }\end{array}$ & Cat\# 2775; RRID: AB_915950 \\
\hline Rabbit polyclonal anti-Cathepsin D & Proteintech Group & Cat\# 21327-1-AP; RRID: AB_10733646 \\
\hline Mouse monoclonal anti-LAMP2 & DSHB & Cat\# H4B4; RRID: AB_2134755 \\
\hline Rabbit polyclonal anti-IGF2R & Proteintech Group & Cat\# 20253-1-AP; RRID: AB_10859779 \\
\hline Mouse monoclonal anti-TfR & Thermo Fisher & Cat\# 13-6800; RRID: AB_2533029 \\
\hline Rabbit polyclonal anti-E-cadherin & Proteintech Group & Cat\# 20874-1-AP; RRID: AB_10697811 \\
\hline Sheep polyclonal anti-LAMP1 (surface) & Thermo Fisher & Cat\# AF4800; RRID: AB_1026176 \\
\hline Mouse monoclonal anti-VSV-G & Gift from David Sheff & $\mathrm{N} / \mathrm{A}$ \\
\hline Mouse monoclonal anti-alpha-Tubulin & DSHB & Cat\# AA4.3; RRID: AB_579793 \\
\hline Mouse monoclonal anti-beta-Actin & Proteintech Group & Cat\# 66009-1-lg; RRID: AB_2687938 \\
\hline
\end{tabular}




\section{REFERENCES}

Ahat, E., Song, Y., Xia, K., Reid, W., Li, J., Bui, S., Zhang, F., Linhardt, R.J., and Wang, Y. (2022). GRASP depletion-mediated Golgi structural defect impairs glycosaminoglycan synthesis, sulfation, and secretion. Cellular and Molecular Life Sciences In press.

Ahat, E., Xiang, Y., Zhang, X., Bekier, M.E., and Wang, Y. (2019). GRASP depletion-mediated Golgi destruction decreases cell adhesion and migration via the reduction of alpha5beta1 integrin. Mol Biol Cell 30, 766-777.

Aviner, R., and Frydman, J. (2020). Proteostasis in Viral Infection: Unfolding the Complex VirusChaperone Interplay. Cold Spring Harb Perspect Biol 12.

Bekier, M.E., 2nd, Wang, L., Li, J., Huang, H., Tang, D., Zhang, X., and Wang, Y. (2017). Knockout of the Golgi stacking proteins GRASP55 and GRASP65 impairs Golgi structure and function. Mol Biol Cell 28, 2833-2842.

Bisel, B., Wang, Y., Wei, J.H., Xiang, Y., Tang, D., Miron-Mendoza, M., Yoshimura, S., Nakamura, N., and Seemann, J. (2008). ERK regulates Golgi and centrosome orientation towards the leading edge through GRASP65. J Cell Biol 182, 837-843.

Blanco-Melo, D., Nilsson-Payant, B.E., Liu, W.C., Uhl, S., Hoagland, D., Moller, R., Jordan, T.X., Oishi, K., Panis, M., Sachs, D., et al. (2020). Imbalanced Host Response to SARS-CoV-2 Drives Development of COVID-19. Cell 181, 1036-1045 e1039.

Bojkova, D., Klann, K., Koch, B., Widera, M., Krause, D., Ciesek, S., Cinatl, J., and Munch, C. (2020). Proteomics of SARS-CoV-2-infected host cells reveals therapy targets. Nature 583, 469-472.

Boncompain, G., Divoux, S., Gareil, N., de Forges, H., Lescure, A., Latreche, L., Mercanti, V., Jollivet, F., Raposo, G., and Perez, F. (2012). Synchronization of secretory protein traffic in populations of cells. Nat Methods 9, 493-498.

Chen, D., Zheng, Q., Sun, L., Ji, M., Li, Y., Deng, H., and Zhang, H. (2021). ORF3a of SARS-CoV-2 promotes lysosomal exocytosis-mediated viral egress. Dev Cell 56, 3250-3263 e3255.

Cortese, M., Lee, J.Y., Cerikan, B., Neufeldt, C.J., Oorschot, V.M.J., Kohrer, S., Hennies, J., Schieber, N.L., Ronchi, P., Mizzon, G., et al. (2020). Integrative Imaging Reveals SARS-CoV-2-Induced Reshaping of Subcellular Morphologies. Cell Host Microbe 28, 853-866 e855.

Dittmar, M., Lee, J.S., Whig, K., Segrist, E., Li, M., Kamalia, B., Castellana, L., Ayyanathan, K., Cardenas-Diaz, F.L., Morrisey, E.E., et al. (2021). Drug repurposing screens reveal cell-typespecific entry pathways and FDA-approved drugs active against SARS-Cov-2. Cell Rep 35, 108959.

Eymieux, S., Uzbekov, R., Rouille, Y., Blanchard, E., Hourioux, C., Dubuisson, J., Belouzard, S., and Roingeard, P. (2021). Secretory Vesicles Are the Principal Means of SARS-CoV-2 Egress. Cells 
10.

Freundt, E.C., Yu, L., Goldsmith, C.S., Welsh, S., Cheng, A., Yount, B., Liu, W., Frieman, M.B., Buchholz, U.J., Screaton, G.R., et al. (2010). The open reading frame 3a protein of severe acute respiratory syndrome-associated coronavirus promotes membrane rearrangement and cell death. J Virol 84, 1097-1109.

Ghosh, S., Dellibovi-Ragheb, T.A., Kerviel, A., Pak, E., Qiu, Q., Fisher, M., Takvorian, P.M., Bleck, C., Hsu, V.W., Fehr, A.R., et al. (2020). beta-Coronaviruses Use Lysosomes for Egress Instead of the Biosynthetic Secretory Pathway. Cell 183, 1520-1535 e1514.

Gonzales, R.R., and Machamer, C.E. (2021). The SARS CoV-1 3a protein disrupts Golgi complex morphology and cargo trafficking. bioRxiv : the preprint server for biology.

Gordon, D.E., Jang, G.M., Bouhaddou, M., Xu, J., Obernier, K., White, K.M., O'Meara, M.J., Rezelj, V.V., Guo, J.Z., Swaney, D.L., et al. (2020). A SARS-CoV-2 protein interaction map reveals targets for drug repurposing. Nature 583, 459-468.

Gorshkov, K., Chen, C.Z., Bostwick, R., Rasmussen, L., Tran, B.N., Cheng, Y.S., Xu, M., Pradhan, M., Henderson, M., Zhu, W., et al. (2021). The SARS-CoV-2 Cytopathic Effect Is Blocked by Lysosome Alkalizing Small Molecules. ACS infectious diseases 7, 1389-1408.

Hoffmann, M., Kleine-Weber, H., Schroeder, S., Kruger, N., Herrler, T., Erichsen, S., Schiergens, T.S., Herrler, G., Wu, N.H., Nitsche, A., et al. (2020a). SARS-CoV-2 Cell Entry Depends on ACE2 and TMPRSS2 and Is Blocked by a Clinically Proven Protease Inhibitor. Cell 181, 271-280 e278.

Hoffmann, M., Mosbauer, K., Hofmann-Winkler, H., Kaul, A., Kleine-Weber, H., Kruger, N., Gassen, N.C., Muller, M.A., Drosten, C., and Pohlmann, S. (2020b). Chloroquine does not inhibit infection of human lung cells with SARS-CoV-2. Nature 585, 588-590.

Huang, S., and Wang, Y. (2017). Golgi structure formation, function, and post-translational modifications in mammalian cells. F1000Res 6, 2050.

Huynh, C., and Andrews, N.W. (2005). The small chemical vacuolin-1 alters the morphology of lysosomes without inhibiting Ca2+-regulated exocytosis. EMBO reports 6, 843-847.

Ireland, S., Huang, H., Zhang, J., Li, J., and Wang, Y. (2020a). Hydrogen peroxide induces Arl1 degradation and impairs Golgi-mediated trafficking. Mol Biol Cell 31, 1931-1942.

Ireland, S., Ramnarayanan, S., Fu, M., Zhang, X., Zhang, J., Li, J., Emebo, D., and Wang, Y. (2020b). Cytosolic $\mathrm{Ca}(2+)$ Modulates Golgi Structure Through PKCalpha-Mediated GRASP55 Phosphorylation. iScience 23, 100952.

Khoury, D.S., Wheatley, A.K., Ramuta, M.D., Reynaldi, A., Cromer, D., Subbarao, K., O'Connor, D.H., Kent, S.J., and Davenport, M.P. (2020). Measuring immunity to SARS-CoV-2 infection: comparing assays and animal models. Nat Rev Immunol 20, 727-738. 
Lane, J.D., Lucocq, J., Pryde, J., Barr, F.A., Woodman, P.G., Allan, V.J., and Lowe, M. (2002). Caspase-mediated cleavage of the stacking protein GRASP65 is required for Golgi fragmentation during apoptosis. J Cell Biol 156, 495-509.

Matlin, K.S., and Simons, K. (1983). Reduced temperature prevents transfer of a membrane glycoprotein to the cell surface but does not prevent terminal glycosylation. Cell 34, 233-243.

Nüchel, J., Tauber, M., Nolte, J.L., Mörgelin, M., Türk, C., Eckes, B., Demetriades, C., and Plomann, M. (2021). An mTORC1-GRASP55 signaling axis controls unconventional secretion to reshape the extracellular proteome upon stress. Mol Cell.

Planas, D., Veyer, D., Baidaliuk, A., Staropoli, I., Guivel-Benhassine, F., Rajah, M.M., Planchais, C., Porrot, F., Robillard, N., Puech, J., et al. (2021). Reduced sensitivity of SARS-CoV-2 variant Delta to antibody neutralization. Nature 596, 276-280.

Ponnambalam, S., Rabouille, C., Luzio, J.P., Nilsson, T., and Warren, G. (1994). The TGN38 glycoprotein contains two non-overlapping signals that mediate localization to the trans-Golgi network. J Cell Biol 125, 253-268.

Qiu, J., Sheedlo, M.J., Yu, K., Tan, Y., Nakayasu, E.S., Das, C., Liu, X., and Luo, Z.Q. (2016). Ubiquitination independent of E1 and E2 enzymes by bacterial effectors. Nature 533, 120-124.

Reaves, B., Horn, M., and Banting, G. (1993). TGN38/41 recycles between the cell surface and the TGN: brefeldin A affects its rate of return to the TGN. Mol Biol Cell 4, 93-105.

Sanda, M., Morrison, L., and Goldman, R. (2021). N- and O-Glycosylation of the SARS-CoV-2 Spike Protein. Anal Chem 93, 2003-2009.

Shang, J., Wan, Y., Luo, C., Ye, G., Geng, Q., Auerbach, A., and Li, F. (2020). Cell entry mechanisms of SARS-CoV-2. Proc Natl Acad Sci U S A 117, 11727-11734.

Sherman, E.J., Mirabelli, C., Tang, V.T., Khan, T.G., Kennedy, A.A., Graham, S.E., Willer, C.J., Tai, A.W., Sexton, J.Z., Wobus, C.E., et al. (2021). Identification of ACE2 modifiers by CRISPR screening. bioRxiv : the preprint server for biology.

Shorter, J., Watson, R., Giannakou, M.E., Clarke, M., Warren, G., and Barr, F.A. (1999). GRASP55, a second mammalian GRASP protein involved in the stacking of Golgi cisternae in a cell-free system. Embo J 18, 4949-4960.

Sun, J., Ye, F., Wu, A., Yang, R., Pan, M., Sheng, J., Zhu, W., Mao, L., Wang, M., Xia, Z., et al. (2020). Comparative Transcriptome Analysis Reveals the Intensive Early Stage Responses of Host Cells to SARS-CoV-2 Infection. Front Microbiol 11, 593857.

Tang, D., and Wang, Y. (2013). Cell cycle regulation of Golgi membrane dynamics. Trends Cell Biol 23, 296-304.

Tang, D., Xiang, Y., and Wang, Y. (2010a). Reconstitution of the cell cycle-regulated Golgi 
disassembly and reassembly in a cell-free system. Nat Protoc 5, 758-772.

Tang, D., Yuan, H., Vielemeyer, O., Perez, F., and Wang, Y. (2012). Sequential phosphorylation of

GRASP65 during mitotic Golgi disassembly. Biol Open 1, 1204-1214.

Tang, D., Yuan, H., and Wang, Y. (2010b). The Role of GRASP65 in Golgi Cisternal Stacking and

Cell Cycle Progression. Traffic 11, 827-842.

Tian, W., Li, D., Zhang, N., Bai, G., Yuan, K., Xiao, H., Gao, F., Chen, Y., Wong, C.C.L., and Gao, G.F. (2021). O-glycosylation pattern of the SARS-CoV-2 spike protein reveals an "O-Follow-N" rule. Cell Res.

Wang, Y., Satoh, A., and Warren, G. (2005). Mapping the functional domains of the Golgi stacking factor GRASP65. J Biol Chem 280, 4921-4928.

Wang, Y., Seemann, J., Pypaert, M., Shorter, J., and Warren, G. (2003). A direct role for GRASP65 as a mitotically regulated Golgi stacking factor. Embo J 22, 3279-3290.

Wang, Y., Wei, J.H., Bisel, B., Tang, D., and Seemann, J. (2008). Golgi Cisternal Unstacking Stimulates COPI Vesicle Budding and Protein Transport. PLoS ONE 3, e1647.

Welsch, S., Muller, B., and Krausslich, H.G. (2007). More than one door - Budding of enveloped viruses through cellular membranes. FEBS Lett 581, 2089-2097.

Westerbeck, J.W., and Machamer, C.E. (2015). A Coronavirus E Protein Is Present in Two Distinct Pools with Different Effects on Assembly and the Secretory Pathway. J Virol 89, 9313-9323.

Westerbeck, J.W., and Machamer, C.E. (2019). The Infectious Bronchitis Coronavirus Envelope Protein Alters Golgi pH To Protect the Spike Protein and Promote the Release of Infectious Virus. J Virol 93.

Xiang, Y., and Wang, Y. (2010). GRASP55 and GRASP65 play complementary and essential roles in Golgi cisternal stacking. J Cell Biol 188, 237-251.

Xiang, Y., Zhang, X., Nix, D.B., Katoh, T., Aoki, K., Tiemeyer, M., and Wang, Y. (2013). Regulation of protein glycosylation and sorting by the Golgi matrix proteins GRASP55/65. Nat Commun 4, 1659.

Zhang, J., Cruz-Cosme, R., Zhuang, M.W., Liu, D., Liu, Y., Teng, S., Wang, P.H., and Tang, Q. (2020). A systemic and molecular study of subcellular localization of SARS-CoV-2 proteins. Signal transduction and targeted therapy 5, 269.

Zhang, X., Wang, L., Lak, B., Li, J., Jokitalo, E., and Wang, Y. (2018). GRASP55 Senses Glucose Deprivation through O-GlcNAcylation to Promote Autophagosome-Lysosome Fusion. Dev Cell 45, 245-261 e246.

Zhang, X., and Wang, Y. (2015). GRASPs in Golgi Structure and Function. Frontiers in Cell and Developmental Biology 3, 84 . 
Zhang, X., and Wang, Y. (2016). Glycosylation Quality Control by the Golgi Structure. J Mol Biol 428, 3183-3193.

Zhang, X., and Wang, Y. (2018). The Golgi stacking protein GORASP2/GRASP55 serves as an energy sensor to promote autophagosome maturation under glucose starvation. Autophagy 14, 1649-1651.

Zhang, X., and Wang, Y. (2020). Nonredundant Roles of GRASP55 and GRASP65 in the Golgi Apparatus and Beyond. Trends Biochem Sci 45, 1065-1079. 